\title{
Complexity Study on the Unsteady Flow Field and Aerodynamic Noise of High-Speed Railways on Bridges
}

\author{
Jufeng Su $\left(\mathbb{D},{ }^{1}\right.$ Yamin Sun $\mathbb{D D}^{1}$, and Yuyang Liu $\mathbb{D}^{2}$ \\ ${ }^{1}$ School of Highway, Chang'an University, Xi'an, Shaanxi Province 710064, China \\ ${ }^{2}$ School of Civil Engineering, Chang'an University, Xi'an, Shaanxi Province 710064, China \\ Correspondence should be addressed to Jufeng Su; sujf10@chd.edu.cn
}

Received 28 April 2018; Revised 4 June 2018; Accepted 10 June 2018; Published 16 July 2018

Academic Editor: Changzhi Wu

Copyright ( 2018 Jufeng Su et al. This is an open access article distributed under the Creative Commons Attribution License, which permits unrestricted use, distribution, and reproduction in any medium, provided the original work is properly cited.

\begin{abstract}
To study complexity distributions of unsteady flow field and aerodynamic noise of a high-speed railway on bridges, an aerodynamic noise model of a railway was obtained. Meanwhile, detailed structures such as 6 bogies, 3 air conditioning units, 1 pantograph fairing, and 1 pantograph were considered. Numerical simulation was conducted to flow fields around the high-speed railway running on the bridge under a crosswind-free environment, with running speed of $350 \mathrm{~km} / \mathrm{h}$. Hence, unsteady flow behavior characteristics of the complete high-speed railway were obtained. Numerical simulation was conducted to noises of the railway on the bridge in combination with detached eddy simulation and acoustic analogy theory. Meanwhile, the broadband noise model was used for the quantitative analysis on distribution characteristics of the dipole noise source and quadrupole noise source of the high-speed railway on the bridge. Studied results proved that aerodynamic noise of the railway was caused by eddy shedding and fluid separation. Main noise sources of the high-speed railway include areas such as pantographs, train head streamline, bogies, windshield, and an air conditioning unit. Maximum sound pressure level and average sound pressure level of the high-speed railway on the bridge were $2.7 \mathrm{dBA}$ and $2.3 \mathrm{dBA}$, respectively, more than those of the high-speed railway on a flat ground. On the bridge, the maximum sound pressure level of the pantograph on the bridge was $3.1 \mathrm{dBA}$ larger than that on the flat ground. In addition, incoming flows of the high-speed railway on the bridge had greater impacts on aerodynamic noises around the railway compared with those of wake flows. Meanwhile, in directions of incoming flows and wake flows, linear relationship was between the sound pressure levels of noise monitoring points which had different distances from the train head nose and the logarithm of the distances.
\end{abstract}

\section{Introduction}

With the high running speed, the aerodynamic noise of the high-speed railway will increase sharply. Excessive aerodynamic noise will lead to environmental pollution, which would not only bring serious impacts on riding comfort of passengers and normal life of people along railways but would also lead to fatigue damage of equipment and buildings along railways. Large noise has become the major factor which limits the railway speed, which will restrain the sustainable development of high-speed railways [1-4]. As pointed out by Shen, Zhang, and Jin, dynamic environments of common railways mainly involve mechanical and electrical effects, while dynamic environment of high-speed railways mainly involves aerodynamic effects. Hence, the maximum limit is brought by aerodynamic noise [5-7]. In addition, as pointed out by Thompson et al. and Latorre Iglesias et al., noise impact is the environment-friendly problem in highspeed railways. With the increase of running speeds, aerodynamic noise increases rapidly and will become the major noise source of high-speed railways during high-speed running and also the factor hindering further speed acceleration of high-speed railways $[8,9]$.

At present, researches on aerodynamic noise of high-speed railways mainly include theoretical research, experimental research, and numerical simulation. As for experimental research, the experimental methods mainly include a wind tunnel experimental method based on a scaled model, a wind tunnel experimental method based on full-scale components, and a line test method based on full-scale models. Research 
results $[8,10-15]$ show that major aerodynamic noise sources of high-speed railways include the pantograph, bogie, nose tip, pilot, train head, train tail, window, door, joint, skirt board, and so on. Based on wind tunnel experiments, acoustic array technologies and Lighthill acoustic analogy theory, Kitagawa and Nagakura [11] and Nagakura [12] tested aerodynamic noise sources of the Japanese Shinkansen highspeed railway, pointing out that major aerodynamic noise sources of a complete high-speed railway include a pantograph, a bogie, air conditioning units, and so on. Yamazaki et al. [16] conducted the wind tunnel experimental research and field test to a Shinkansen train with the scaling ratio of $1: 5$, finding that joints also belong to main noise sources of high-speed railways. Wakabayashi et al. [17] employed measures such as a low-noise pantograph, pantograph fairing sound insulation plates, and baseplate sound adsorption materials to the linear test trains FASTECH360S and FASTECH360Z. Noise reduction effects of tested trains were obvious. When far-field noise standard requirements were satisfied, the training running speed could reach $330 \mathrm{~km} / \mathrm{h}$. In combination with the original combined train of E3 and $\mathrm{E} 2$, the aerodynamic noise of the reconnected train of FASTECH360S and FASTECH $360 \mathrm{Z}$ was reduced by $4-5 \mathrm{dBA}$. Kurita summarized aerodynamic noise reduction measures of E5, including the application of PS9037 low-noise pantograph, low-noise pantograph fairing sound insulation plate, circular diagraph at train end joints, all-wrapped skirt boards on bogies, and sound absorption materials on train bottom. The above methods were applied to a low-noise design of E5 trains. On the premise that noise standards can be satisfied, the commercial running speed of E5 trains on Shinkansen will reach $320 \mathrm{~km} / \mathrm{h}$ [18]. Noh et al. used the wave beam forming experiment with delay and summation to conduct experimental research of aerodynamic noise sources of a high-speed train, finding aerodynamic noise spectrum characteristics that noise sources of the railway mainly include a head nose tip, a bogie, a pantograph, and train end joints, wherein the aerodynamic noise spectrum of the head noise tip was mainly distributed in low-frequency areas under $1000 \mathrm{~Hz}$; noise of the pantograph and the pantograph fairing was mainly distributed in high-frequency parts of over $2000 \mathrm{~Hz}$; main frequency energy at train end joints was mainly concreted under $500 \mathrm{~Hz}$ [19]. Xiao and Kang [20] researched longitudinal symmetric faces of the high-speed train, established a large eddy simulation model of longitudinal symmetric faces of the high-speed train, and researched frequency spectrum characteristics and changing rules of aerodynamic noise on the longitudinal symmetric faces, finding optimized appearance at train joints. Liu et al. [21] established a math physical model of three-dimensional flow fields of the head of a high-speed railway, computed far-field noise of the high-speed railway with Lighthill acoustic analogy theory, and computed aerodynamic noise sources on high-speed train surfaces with a broadband noise source model. Sun et al. $[22,23]$ established a three-train high-speed train aerodynamic model, analyzed flow field characteristics at head, carriage joints, tail parts, and other parts of the train, and researched contribution made by different train parts to the aerodynamic noise, wherein the bogie and pantograph were not considered in the model. Huang et al. [24] established an analysis model of bogie aerodynamic noise, mainly researched aerodynamic noise generated from bogie noise sources, and analyzed noise reduction effects brought to radiation noise on both sides during the use of bogie skirt boards.

At present, a lot of researches have been conducted to aerodynamic noise of high-speed railways under open-line working conditions. Aerodynamic flow characteristics and aerodynamic noise of high-speed railways on bridges are rarely researched. Hence, the paper established an aerodynamic model of a high-speed railway and an aerodynamic noise model to analyze unsteady aerodynamic flow of the railway, conducted quantitative analysis on dipole noise sources and quadrupole noise sources of the railway on the bridge in combination with the broadband noise source model, and researched far-field noise characteristics of the railway in combination with DES and FW-H equations, obtaining aerodynamic flow behavior characteristics of the high-speed railway on the bridge, far-field aerodynamic noise distribution of the railway, aerodynamic noise radiation characteristics on the bridge, and so on.

\section{Analysis Method of Aerodynamic Noise of High-Speed Railways}

A classic FW-H equation was sourced by the Lighthill equation. Sound field characteristics of pulsation sound sources can be further solved if flow field information is collected. Formula (1) indicates a FW-H integral form obtained through Green solution with free space [25]:

$$
\begin{aligned}
p^{\prime}(\mathbf{x}, t)= & \frac{\partial^{2}}{\partial x_{i} x_{j}} \int_{f>0}\left[\frac{T_{i j}}{4 \pi|\mathbf{x}-\mathbf{y}|}\right] d V-\frac{\partial}{\partial x_{i}} \int_{f=0}\left[\frac{L_{i j} n_{j}}{4 \pi|\mathbf{x}-\mathbf{y}|}\right] d S \\
& +\frac{\partial}{\partial t} \int_{f=0}\left[\frac{Q_{i} n_{i}}{4 \pi|\mathbf{x}-\mathbf{y}|}\right] d S .
\end{aligned}
$$

In formula (1), $p^{\prime}(\mathbf{x}, t)$ denotes the pulsation sound pressure value of the noise reception point $\mathbf{x}$ at the specific time $t, Q_{i}$ denotes the thickness noise, and $L_{i j}$ denotes the loading noise.

In the flow fluid with a low Mach number, $\rho^{\prime} / \rho_{0}<1$. Hence, the pulsation sound pressure $p^{\prime}(\mathbf{x}, t)$ could be approximated to

$$
p^{\prime}(\mathbf{x}, t)=\rho^{\prime}(\mathbf{x}, t) c_{0}^{2}=c_{0}^{2}\left(\rho(\mathbf{x}, t)-\rho_{0}(\mathbf{x}, t)\right) .
$$

Hence, noise sources on the right end of the FW-H integral form in Formula (1) are as follows:

$$
\begin{aligned}
& Q_{i}=\rho\left(u_{i}-v_{i}\right)+\rho_{0} v_{i}, \\
& L_{i j}=\left(p-p_{0}\right) \delta_{i j}+\rho u_{i}\left(u_{j}-v_{j}\right), \\
& T_{i j}=\rho u_{i} u_{j}+\left[\left(p-p_{0}\right)-c_{0}^{2} \rho^{\prime}\right] \delta_{i j}-\boldsymbol{\tau}_{i j} .
\end{aligned}
$$

In formula (3), $u_{i}$ and $v_{i}$ denote speed components on the control face and $\boldsymbol{\tau}_{i j}$ denotes a viscidity pressure tensor. 
The first item on the right end of FW-H equation is a monopole noise source determined with the acceleration on the surface of the control face and exists in the superficial area of the control face; the second item on the right end of FW-H equation depends on characteristics of unsteady aerodynamic flow behaviors on the fixed surface and only exists on the surface of the control face, while it is a dipole noise source; the third item on the right end of $\mathrm{FW}-\mathrm{H}$ equation is a Lighthill stress tensor and exists outside the surface of the control face, while it is a quadrupole noise source.

When a high-speed train runs at a certain speed, the train body surface can be deemed to be rigid, while the volume pulsation quantity is nearly zero. Hence, it is not necessary to consider monopole noise sources. The intensity ratio of the quadrupole sound source and dipole sound source in the flow field is equal to the Mach number. Motion of a high-speed train still belongs to low-speed motion, wherein the noise intensity of the quadrupole sound source is smaller than that of the dipole sound source. Hence, the quadrupole sound source item can be ignored. In other words, only the high-speed train aerodynamic noise caused by dipole sound sources is considered.

\section{Numerical Model of Aerodynamic Noise of High-Speed Railways}

In this paper, the CHR3 high-speed railway was researched. Three railways were selected for the marshalling, including a head railway, a tail railway, and a mid railway with a pantograph, wherein each railway includes a front bogie and a rear bogie. Bodies were not smooth. Hence, the model was simplified; some small components were ignored, and wrapped windshields on joints were considered. The simplified model of high-speed railways is shown in Figure 1. The head railway and the tail railway were set symmetrically. Size parameters of the high-speed railway which include length, width, and height are $78.4 \mathrm{~m}, 3.3 \mathrm{~m}$, and $3.6 \mathrm{~m}$. The horizontal cross section diagram of $\mathrm{CRH} 3$ when it is passing a bridge is shown in Figure 2. The bridge is $13.2 \mathrm{~m}$ wide and $10 \mathrm{~m}$ higher over the ground, with the linear spacing of $5 \mathrm{~m}$ on the bridge.

Indeed, the computational model of high-speed railways in this article is very huge, but we did not consider using the scaled model to complete the numerical computation because the scaled model will reduce the computational accuracy of the computational model. Moreover, we have a computer with a high performance, and the computational time will be relatively high. Computational domain of aerodynamic noise of the high-speed railway on the bridge is shown in Figure 3. The computation domain is $358.4 \mathrm{~m}$ long, $40 \mathrm{~m}$ wide, and $40 \mathrm{~m}$ high, wherein the head railway nose tip is $80 \mathrm{~m}$ away from the flow entrance, the tail railway nose tip is $200 \mathrm{~m}$ away from the flow exit, and the distance between the railway and the rail ground is $0.5 \mathrm{~m}$. The cross section abcd right in front of the high-speed railway is the entrance boundary and set as the speed entrance condition, where the running speed was $350 \mathrm{~km} / \mathrm{h}(97.2222 \mathrm{~m} / \mathrm{s})$ during computation. The cross section efgh right behind the tail railway of the high-speed railway is the exit boundary and set as the pressure exit condition, where the size is one standard atmospheric pressure. Cross section bfgc right above the high-speed railway, the left cross section cghd on the left, and the cross section aefb on the right are set as symmetric boundary conditions. High-speed railway surface and bridge are set as fixed boundaries, namely boundary conditions without slippage wall faces. In order to simulate ground effect, the ground aehd is set as a slippage ground, while the slippage speed is equal to the running speed.

Trimmer meshes were divided by STAR-CCM+, and the final result is shown in Figure 4. The following parameters are set: maximum outfield mesh edge length of $2500 \mathrm{~mm}$, maximum mesh edge length of $80 \mathrm{~mm}$ on the surface, maximum mesh edge length of $30 \mathrm{~mm}$ on the surface of an air conditioning unit, maximum mesh edge length of $15 \mathrm{~mm}$ on the pantograph, and maximum mesh edge length of $40 \mathrm{~mm}$ on the bogie surface. In order to consider impacts of fluid flowing on the train surface more accurately, boundary layer mesh division was conducted on the surface, wherein the normal distance between the first layer of meshes to the wall face was $0.01 \mathrm{~mm}$; there are 15 layers of boundary layer meshes; the growth rate is 1.2. In order to reduce flow impacts of wake flows on the surface, mesh densification was conducted to areas around the train, tail parts of the train, rear sides of pantograph, and leeward side of the train. There are about $6.578 \times 10^{7}$ meshes in total. In the computational model, there are a lot of different parts. Hard and soft connections were used among them. Hard connections were simulated to use the conodes, while soft connections were simulated to use the spring.

\section{Distribution Characteristics of Unsteady Flow Field of High-Speed Railways on Bridges}

Figure 5 shows pressure contours of different horizontal cross sections near a first-end bogie of the head railway, a first-end bogie of the mid railway, and a first-end bogie of the tail railway. Figure 6 gives the contour of pressure distribution on the bridge surface. Through comparative analysis on the contour surface diagram of pressure around the railway body in Figures 5 and 6, we can find that near the head railway bogie, pressure impacts were wide around the railway. There were a lot of negative pressure areas near one first-end bogie of the head railway. There were a lot of positive pressure areas on the top of the railway. Fluids of the bogie area were located in the negative pressure areas. Hence, lift force increase of the head railway can be further caused. The lift force direction of the head railway was downward. Pressure at one first-end bogie of the mid railway was located in the positive pressure area. Pressure did not change a lot in the bogie area. Obviously, the aerodynamic lift force borne by the mid railway was upward. Most pressures around one first-end bogie of the tail railway were located in the positive pressure area. In comparison with the head railway, a lot of position pressures were distributed in the tail area, while the negative pressure amplitudes were smaller than those in the first-end bogie area of the head railway. Obviously, the tail railway was greatly impacted by large upward lift force. Due to existence of the bridge structure, pressure distribution was messy in the bogie area, leading to large pulsation 


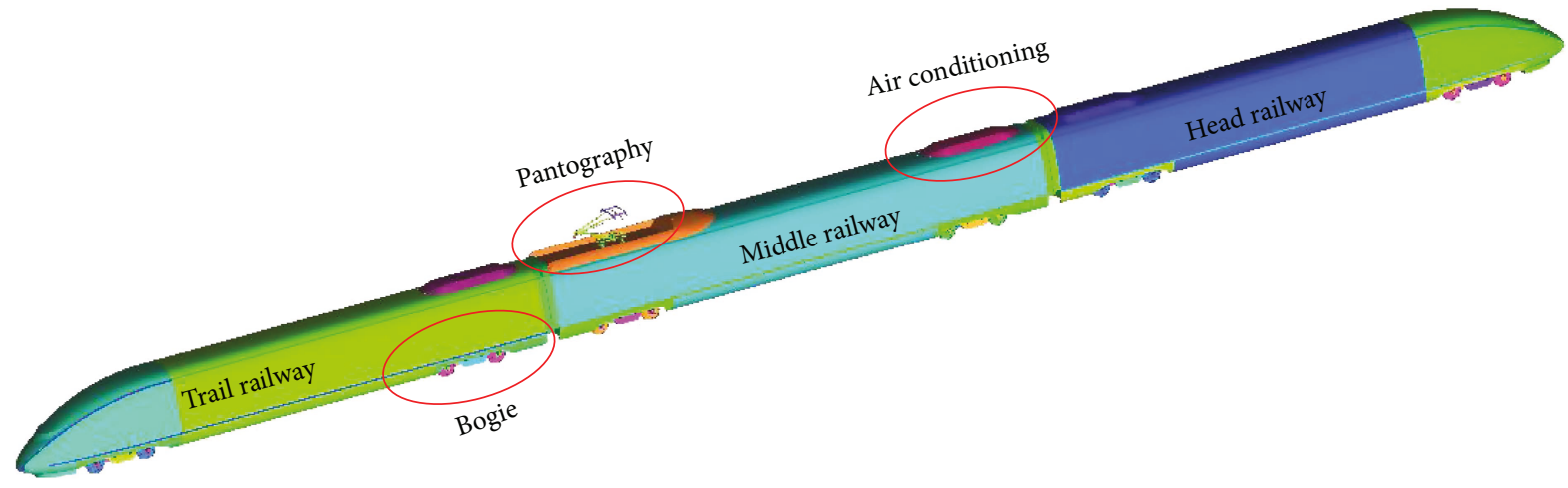

FIGURE 1: Numerical model of CRH3 high-speed railways.

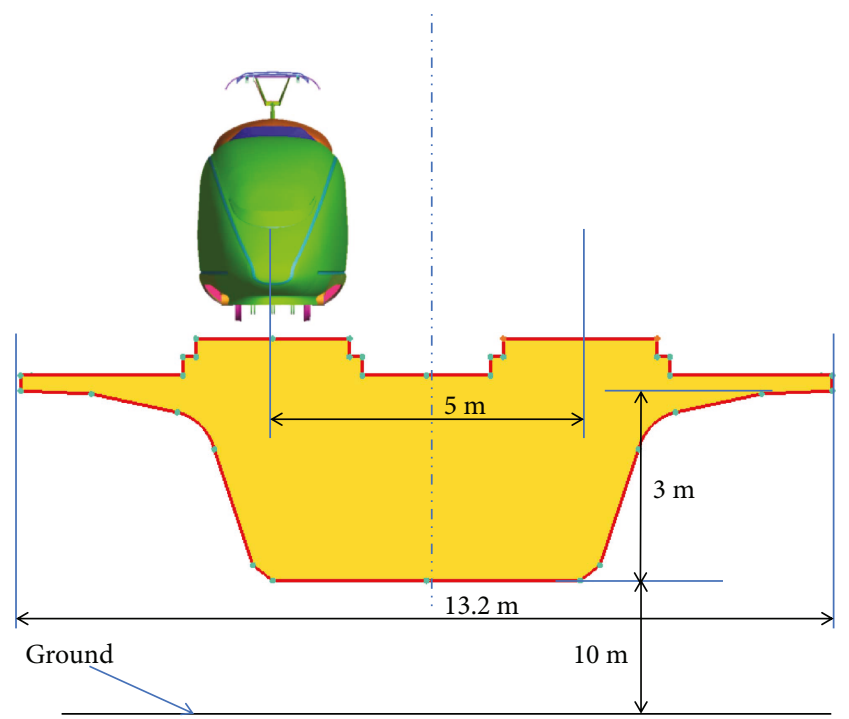

FIGURE 2: Diagram of horizontal cross section during the passing of high-speed railways on bridges.

pressures on the track faces under the railway body. Large positive pressures were distributed on the bridge track board under the railway body. Most track places on the front side of the head train were distributed in negative pressure areas.

To obtain the pulsation pressure at one point of the railway body surface, pulsation pressure monitoring was conducted to the point during numerical simulation. Hence, the pressure-time interval curve of a point on the train surface can be obtained. In the paper, the pressure coefficient $C_{\mathrm{p}}$ is defined as follows:

$$
C_{\mathrm{p}}=\frac{p-p_{0}}{(1 / 2) \rho u^{2}}
$$

where $p_{0}$ denotes the normal atmospheric pressure, $p_{0}=1 \mathrm{~atm}$ and $u$ denotes the high-speed running speed, $u=97.222 \mathrm{~m} / \mathrm{s}$ $(350 \mathrm{~km} / \mathrm{h})$.

Figure 7 shows time interval curve comparison of pulsation pressure coefficients of monitoring points near the lateral window of the head railway as well as monitoring points at transition parts from the head streamline type to the nonstreamline type. It is shown in Figure 7 that pulsation pressure coefficients on the high-speed railway surface showed unsteady characteristics during a certain period and had certain periodicity. The average pressure coefficient of monitoring points near the head railway lateral window was 0.2115 , and the pressure coefficient of the monitoring point at the transition position from the head streamline type to the nonstreamline was -0.1526 . Obviously, the pressure coefficients of the lateral window accessory of the head railway were positive, but negative pressures were distributed at transition positions from the head streamline type to the nonstreamline.

The aerodynamic noise source of high-speed railways is mainly the dipole noise. Dipole sound sources on the surface depend on pulsation pressures of the railway surface. In other words, far-field noise radiation can be reflected by size of pulsation pressures on the surface. According to three control equations of flow fields, turbulence energy equation, and turbulent dissipation rate equation, the size of pulsation pressures on the railway surface can be obtained by the turbulence energy $k$ which can assess characteristics of noise distribution on the surface. Expression of turbulence $k$ is $k=\left({\overline{u^{\prime}}}^{2}+{\overline{v^{\prime}}}^{2}+{\overline{w^{\prime}}}^{2}\right) / 2$.

Figure 8 shows turbulence energy distribution on surfaces of the complete high-speed railway, the pantograph area, the head, and the tail. According to analysis in Figure 8, we can find that high turbulence energy was distributed at transition positions between the head nose tip and the nonstreamline positions of the head railway, between firstend air barrier and pantograph area, between the air conditioning unit and pantograph area, and between the pantograph area and second-end air barrier. The pantograph was impacted by turbulence on the front end of the pantograph fairing, so large decrease near-field noise was generated. Turbulence kept on impacting the rear part of the pantograph area. In addition, due to eddy shedding of the pantograph, noise radiation borne by the pantograph area was further intensified. Similarly, high turbulence energy areas existed at the second-end air barrier. Obviously, the second-end air barrier is also the major distribution area of noise sources. Obviously, areas such as the pantograph, pantograph area, nose tip of the head, head pilot, bogie part, and joints are major aerodynamic noise sources of the high-speed railway. 

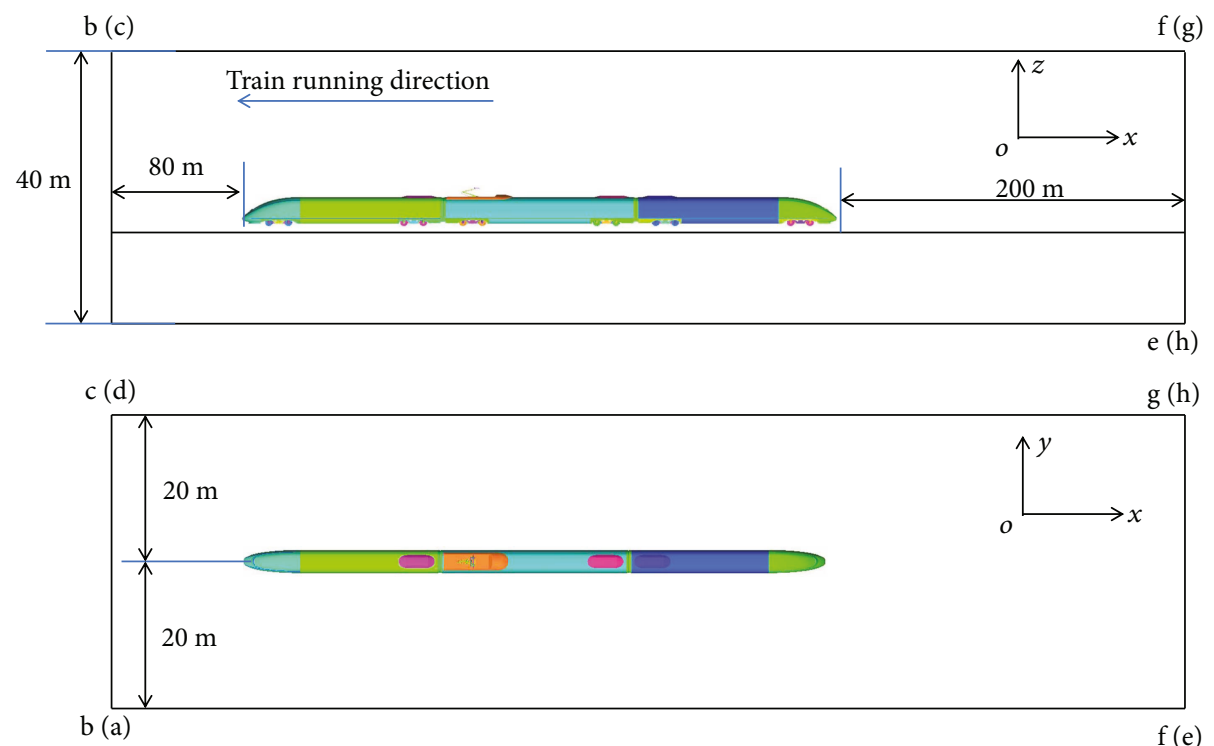

FIGURE 3: Computation domain of high-speed railways on the bridges.

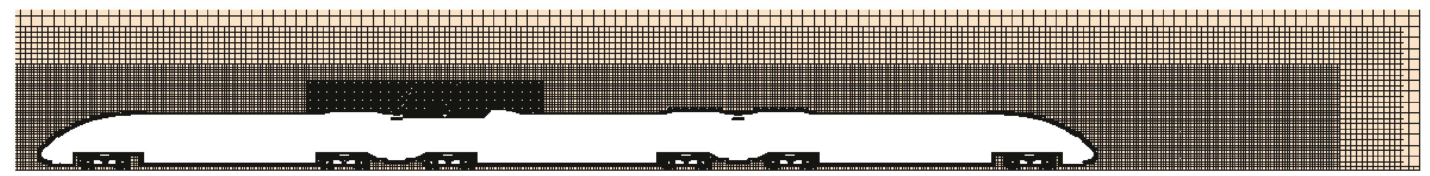

(a) Meshes on the longitudinal center cross section

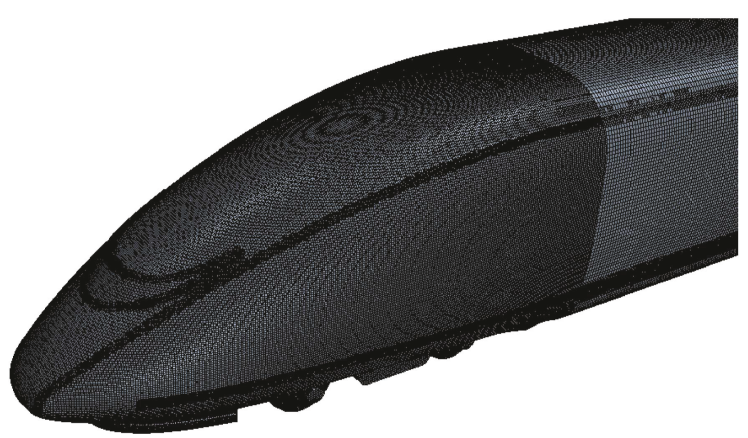

(b) Meshes on the railway head surface

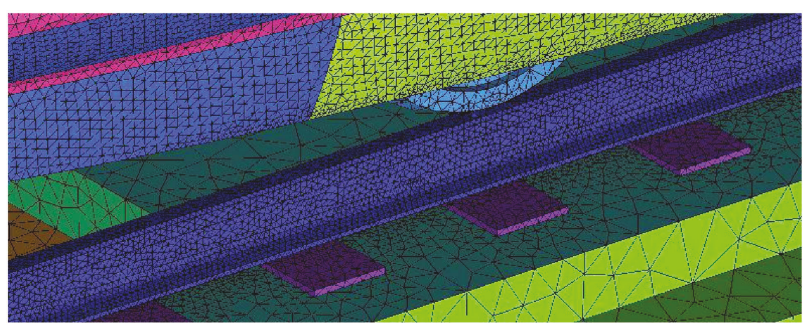

(c) Display of partial meshes of bridge, track, and railway body

Figure 4: Display of discrete meshes of high-speed railways on bridges.

In addition, aerodynamic noise sources of the high-speed railway appeared at positions with easy airflow separation and violent turbulence motion. In fact, in a lot of highspeed railway models, the turbulent kinetic energy on the nose tip of the tail railway should be close to the head railway. However, as shown Figures $8(\mathrm{~d})$ and $8(\mathrm{e})$, the turbulent kinetic energy on the nose tip of the tail railway is obviously less than that of the head railway and the distribution of the turbulent kinetic energy is not very similar because the turbulence eddies near the nose tip of the tail railway were not serious in this model and the geometric shape of this model is very smooth.

Figure 9 shows the vorticity distribution contour of the high-speed railway under the running speed of $350 \mathrm{~km} / \mathrm{h}$ based on Q-code (scale of 0.001). It is shown in Figure 9 that eddies with different scales and rotation directions existed in the head streamline areas (including the first-end bogie of the head railway), second-end bogie areas of the head railway, first-end bogie areas of mid railway, second-end bogie areas of mid railway (including a pantograph, a pantograph fairing, and an air conditioning unit), second-end bogie area of the tail railway, and streamline areas of the tail railway (including the first-end bogie of the tail railway). Obviously, these areas are main aerodynamic noise sources of high-speed railways. The head part of the pantograph head leads to cylindrical turbulent flow which cannot be caused in chassis areas. Band-shaped eddies were formed at the front end of the pantograph fairing and pantograph head. A lot of band-shaped eddies with different scales and different directions got shed and reorganized periodically. Crescent or U-shaped eddies were mainly formed in bogie areas, end joints, and air conditioning unit areas. They are most commonly seen turbulent 
Pressure $(\mathrm{Pa})$

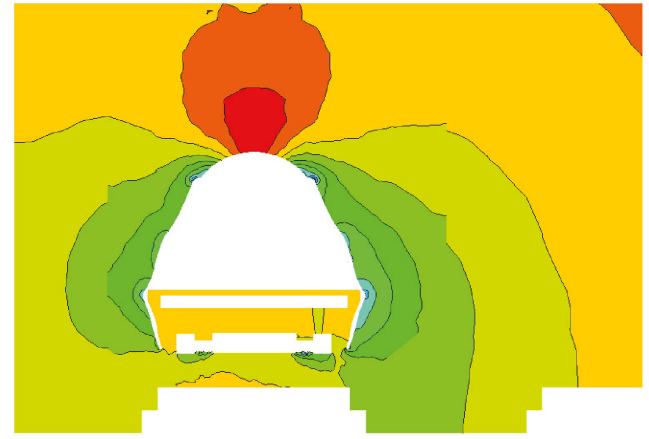

(a) First-end bogie of the head railway

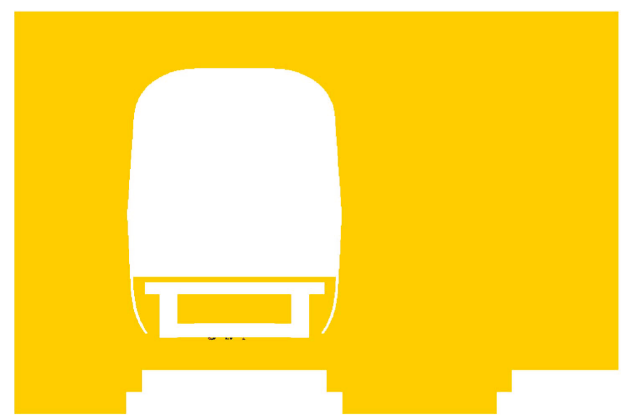

(c) Second-end bogie of the mid railway
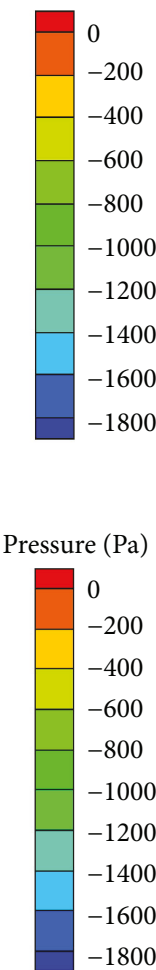

$-1800$

Figure 5: Contours of pressures on different cross sections of high-speed railways.

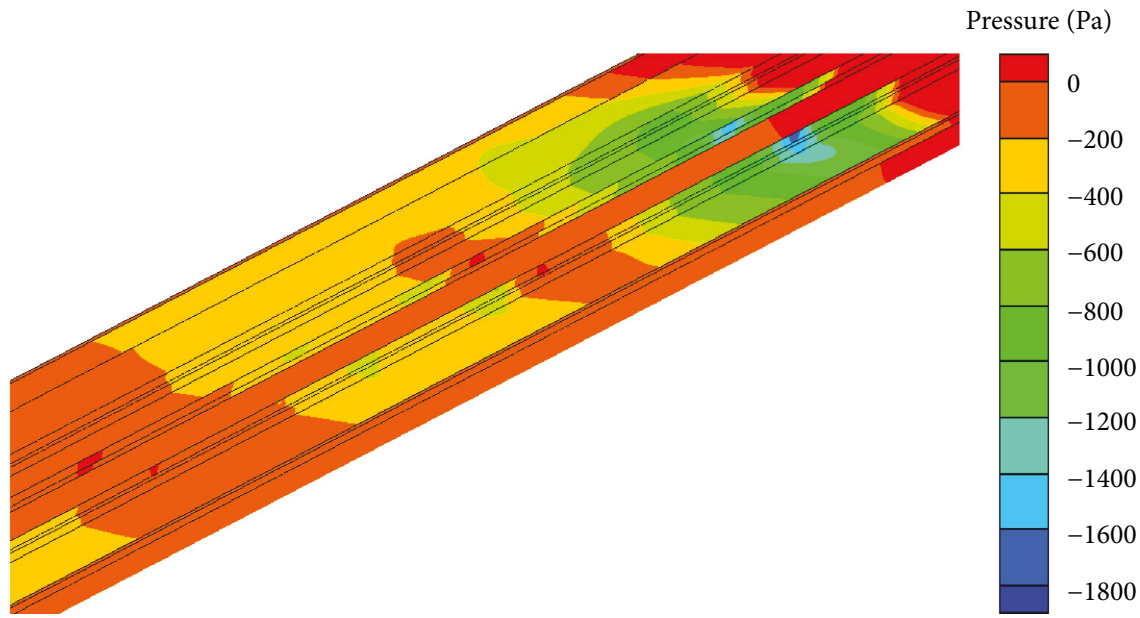

FIGURE 6: Contour of pressure distribution of high-speed railways on bridges.

eddies caused by bogies and end joints. Turbulent eddies shed from the bogie and end joints were large. Energy was mainly contained in large-scale eddies with centralized vorticity. These eddies keep on extending along the flow direction and striking the bogie skirt board and air conditioning unit. Hence, eddies are broken, while smaller eddies are distributed, leading to larger distribution scale scope of eddies. Obviously, eddy shedding and fluid separation of the complete railway are main reasons for the formation of the aerodynamic noise. Meanwhile, the pantograph area is the major
Pressure $(\mathrm{Pa})$
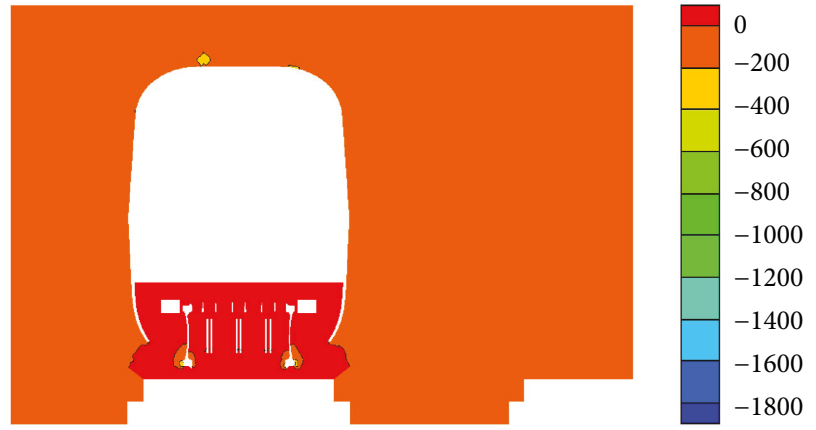

(b) First-end bogie of the mid railway

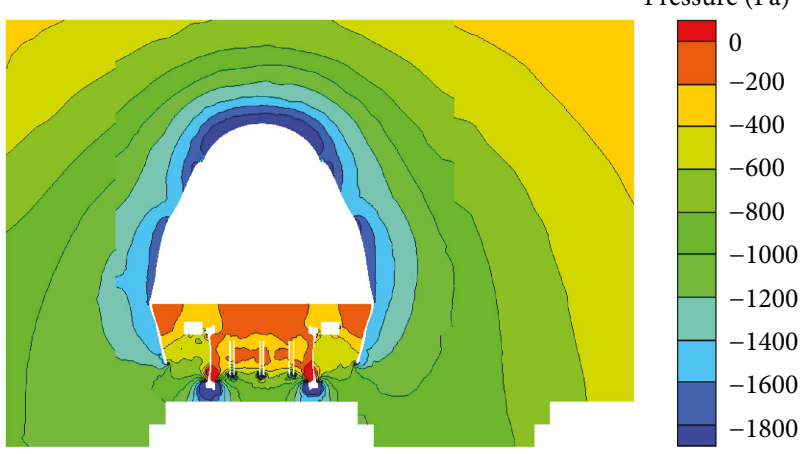

(d) First-end bogie of the tail railway

Pressure $(\mathrm{Pa})$ 


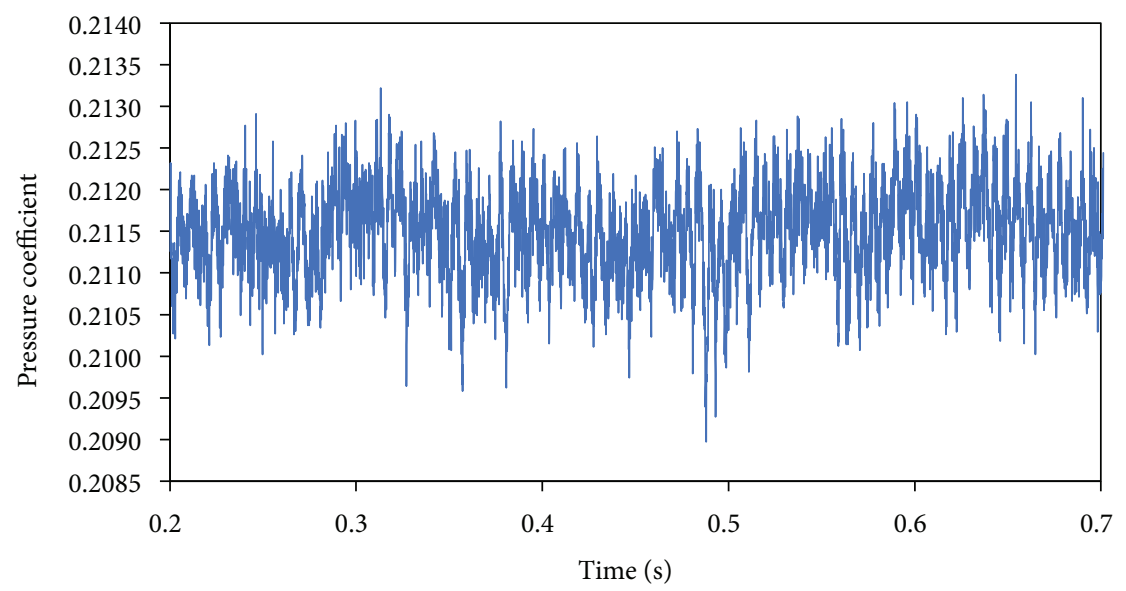

(a) Near lateral window of the head railway

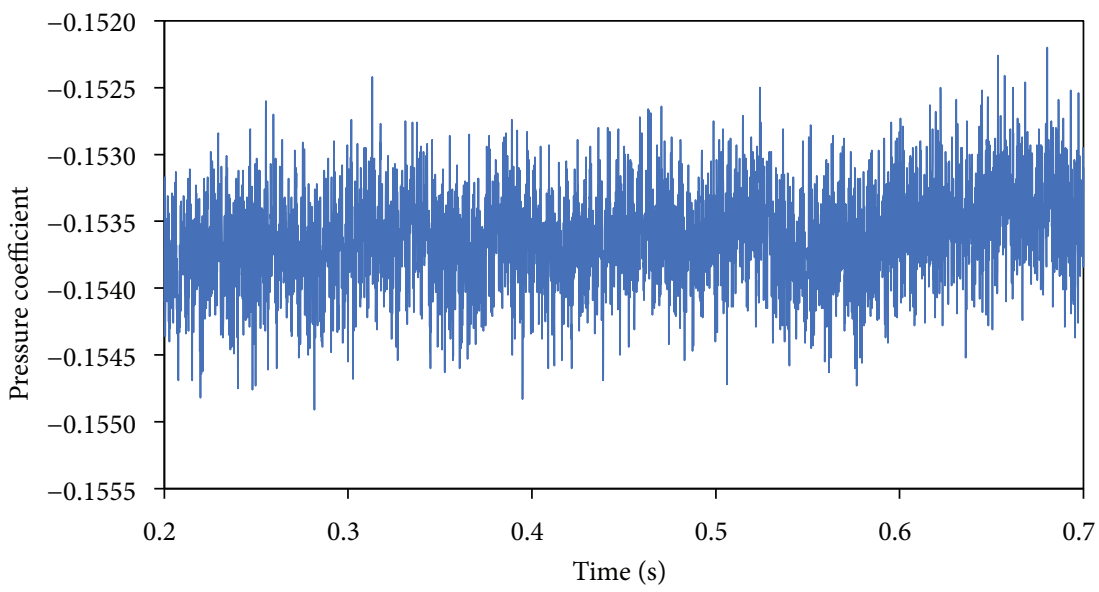

(b) Monitoring point at transition position from the streamline to the nonstreamline

FIGURE 7: Comparison of pressure coefficients at different points of high-speed railways.

model was used in the STAR-CCM+ software. Hence, distribution characteristics of dipole noise intensity of the highspeed railway surface on the bridge could be obtained. Meanwhile, quadrupole space distribution characteristics of aerodynamic noise can be obtained [26-28]. Figure 10 gives the noise power distribution of dipoles on the surface of a highspeed railway running at $350 \mathrm{~km} / \mathrm{h}$ on the bridge. It is shown in Figure 10 that on the bridge, sound power levels at the head railway (nose tip, pilot, and window), pantograph areas (pantograph and pantograph fairing), bogie parts (bogies and bogie skirt board), and end joints reached the local maximums. Obviously, head nose tip, head pilot, head window, pantograph, bogie, and end joint are main aerodynamic nose sources of the high-speed railway. It is shown in Figure 10(d) that main aerodynamic noise sources of the pantograph area are windward positions of parts such as the pantograph head, hinge structure, chassis, and insulator. The maximum sound power was distributed on the balanced arm, with value of 109.6 dBA. The pantograph areas (including a pantograph fairing) had huge airflow disturbance impact on the secondend air barrier, so size and distribution scope of noise power of the second-end air barrier were larger than those of the first-end air barrier, as shown in Figures 10(c) and 10(d).
This is mainly because the second-end air barrier was mainly influenced by eddy shedding and reorganization of the pantograph fairing. It is shown in Figure 10(a) that sound power levels of the first-end bogie of the head railway were larger than those of other bogies, while large sound power levels were distributed widely. Maximum sound power levels at the first-end bogie of the head railway, second-end bogie of the head railway, first-end bogie of the mid railway, secondend bogie of the mid railway, second-end bogie of the tail railway, and first-end bogie of the tail railway were 109.5, 107.2, 103.8, 100.2, 97.8, and 98.9 dBA, respectively. Sound powers at the wheel set side close to the ground, bogie brake discs, and architecture were larger than other bogie components. Hence, we can know that the first-end bogie of the head railway had the maximum sound power level. It is the major aerodynamic noise source of a high-speed railway bogie system.

Figure 11 shows distribution contours of quadrupole noise power levels around the high-speed railway on different longitudinal cross sections, wherein the longitudinal center face coordinate of the high-speed railway was $y=0 \mathrm{~m}$ and the running speed was $350 \mathrm{~km} / \mathrm{s}$. It is shown in Figure 11 that the spatial quadrupole noise propagation of the railway was 


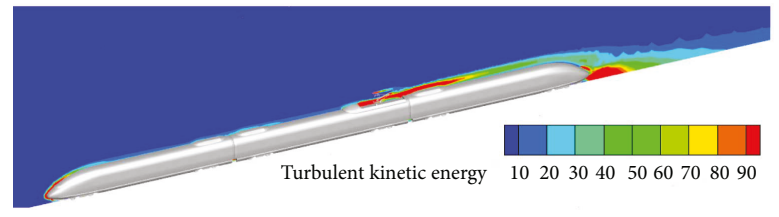

(a) Longitudinal center symmetric face

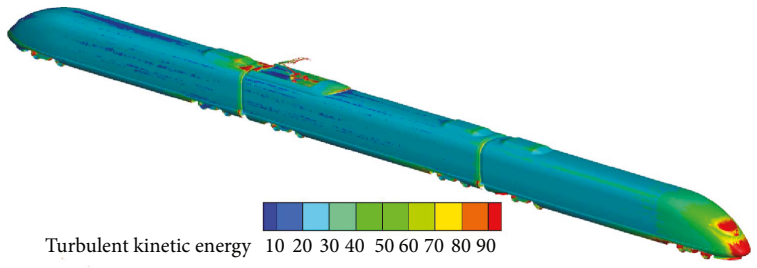

(c) Complete railway

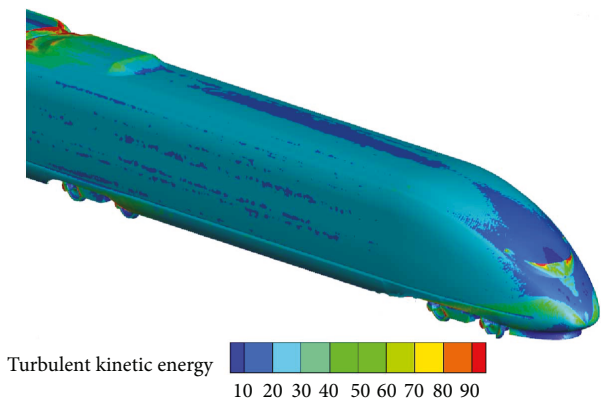

(e) Tail railway

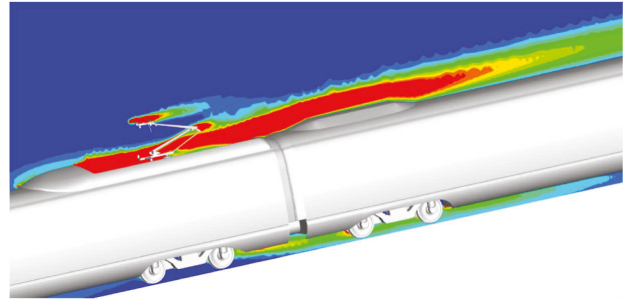

(b) Pantograph area

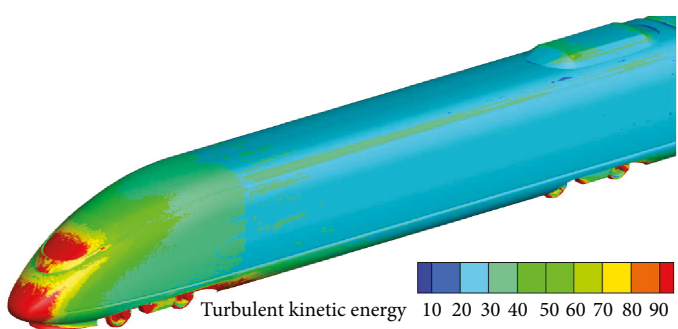

(d) Head railway

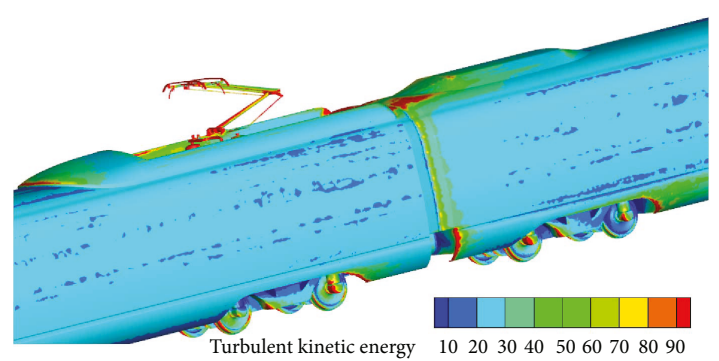

(f) Surface of the pantograph fairing

FIGURE 8: Distribution contour of turbulence energy of high-speed railways.

mainly distributed at the tail railway, while it was related to eddy shedding and reorganization around the railway. Quadrupole noise was distributed widely near the first-end bogie of the head railway, and the size was larger than distribution near other bogies. Obviously, the first-end bogie of the head railway is the main noise source of the railway. The maximum quadrupole noise power level at the position $0.05 \mathrm{~m}$ from the longitudinal center face was distributed at the wake flow of the tail railway. Obviously, eddy shedding on the rear part of tail train on the bridge was the main control factor causing spatial quadrupole noise.

5.2. Characteristics of Far-Field Aerodynamic Noise of HighSpeed Railways on Bridges. Figure 12 shows the Aweighting sound pressure level curve of longitudinal monitoring points of the high-speed railway running at $350 \mathrm{~km} /$ $\mathrm{h}$ on the bridge, wherein the monitoring points were $25 \mathrm{~m}$ away from the track center line and $3.5 \mathrm{~m}$ higher above the track face. 80 noise monitoring points were arranged uniformly along the longitudinal direction of the railway. The distance between the adjacent longitudinal monitoring points was $1 \mathrm{~m}$. Figure 13 shows the far-field sound pressure level curve of the high-speed railway under different road situations (flat ground and bridge). Through comparative analysis on Figures 12 and 13, we can find in Figure 12 that the distribution of longitudinal aerodynamic noise pressure levels of the high-speed railway tended to decrease, wherein the maximum sound pressure level appeared at the rear part of first-end bogie of the head railway. The total sound pressure level reached the maximum value in the area behind the first-end bogie of the head railway. Total sound pressure levels reached maximum values in the second-end bogie area of the head railway, the first-end bogie of mid railway, the second-end bogie area of mid railway, the second-end bogie area of the tail railway, and the first-end bogie of the tail railway. When nose tip of the head railway got transition to $x=6 \mathrm{~m}$ (noise monitoring point 7 ), the far-field noise pressure level increased rapidly with the maximum increment of $10.3 \mathrm{dBA}$. After that, the noise pressure levels of the complete railway did not change a lot. When the head nose tip got transition to $x=6 \mathrm{~m}$, the far-field noise pressure level reached the maximum value $95.6 \mathrm{dBA}$ among all the noise monitoring points. At the streamline part of the tail railway, the noise pressure level got attenuation rapidly, with the maximum attenuation value of $11.4 \mathrm{dBA}$. Meanwhile, total noise pressure levels reached partially large values near the second-end bogie of the head railway, the first-end bogie of mid railway, the second-end bogie of mid railway, the second-end bogie of the tail railway, and the first-end bogie of the tail railway. Maximum sound pressure levels were 


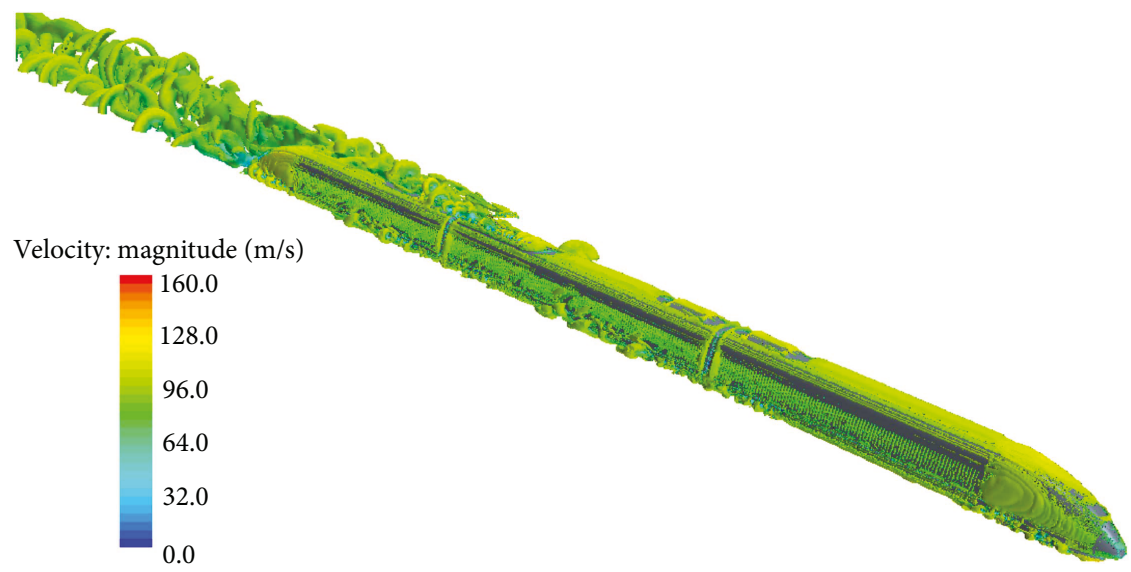

(a) Complete railway

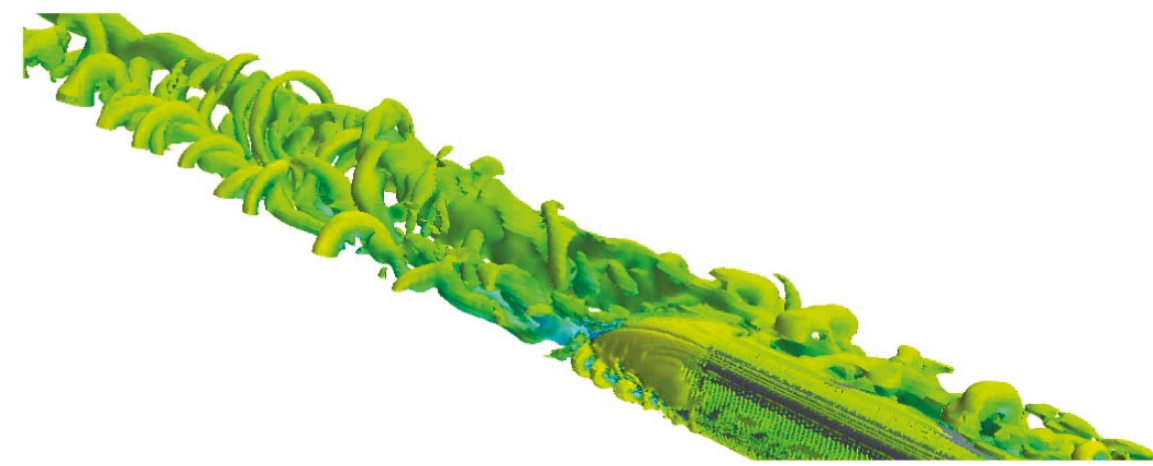

(b) Rear part of the tail railway

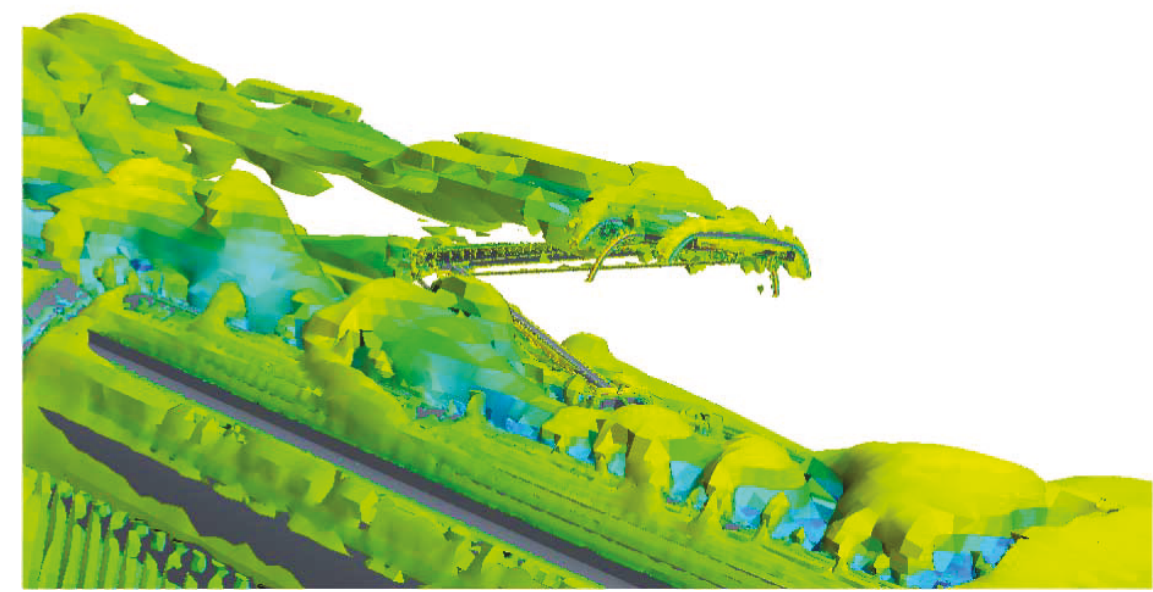

(c) Pantograph area

FIGURE 9: Vorticity distribution diagram of high-speed railways.

93.8 dBA, 93.9 dBA, 92.8 dBA, $92.4 \mathrm{dBA}$, and $90.2 \mathrm{dBA}$. When the high-speed railway ran on the bridge, distribution of far-field aerodynamic noise is characterized in the following aspects: the maximum far-field sound pressure level of the complete railway was $95.6 \mathrm{dBA}$ and the average sound pressure level was $91.9 \mathrm{dBA}$. The maximum sound pressure level in the pantograph fairing area was $92.8 \mathrm{dBA}$. When the high-speed railway ran on the flat ground, distribution of far-field aerodynamic noise is characterized in the following aspects: the maximum far-field sound pressure level of the complete was $92.9 \mathrm{dBA}$ and the average sound pressure level was $89.6 \mathrm{dBA}$. The maximum sound pressure level in the pantograph fairing area was $89.7 \mathrm{dBA}$. Through comparing noise of the railway under different road situations (flat ground and bridge), we can find that the noise performance of the railway was poorer during running on the bridge. The far-field maximum sound pressure level difference of the complete railway was $2.7 \mathrm{dBA}$. The far-field average sound pressure level difference of the complete railway was $2.3 \mathrm{dBA}$. During running on the flat ground, the maximum 


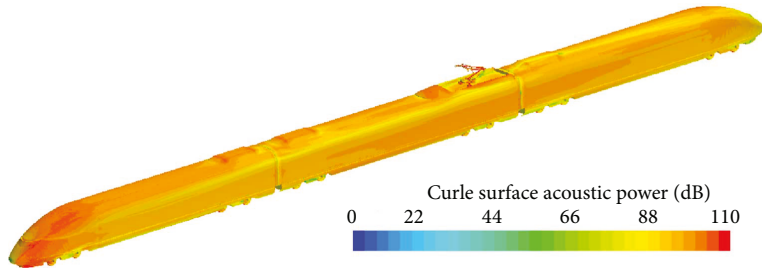

(a) Complete railway

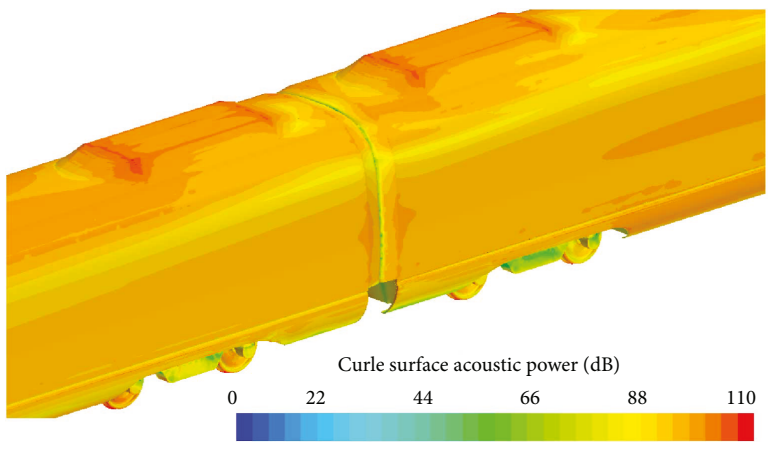

(c) Air conditioning unit

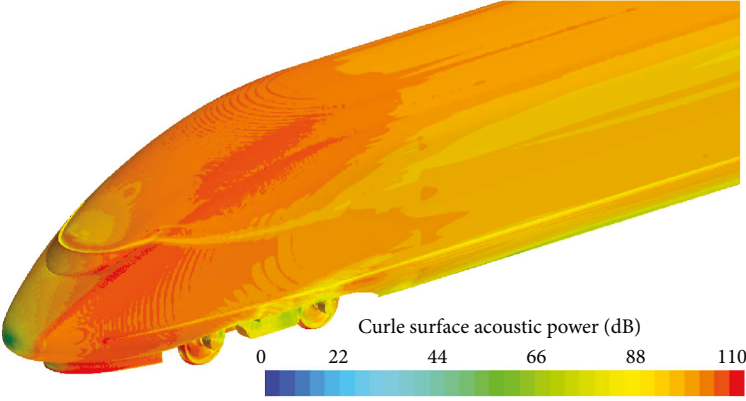

(b) Head railway

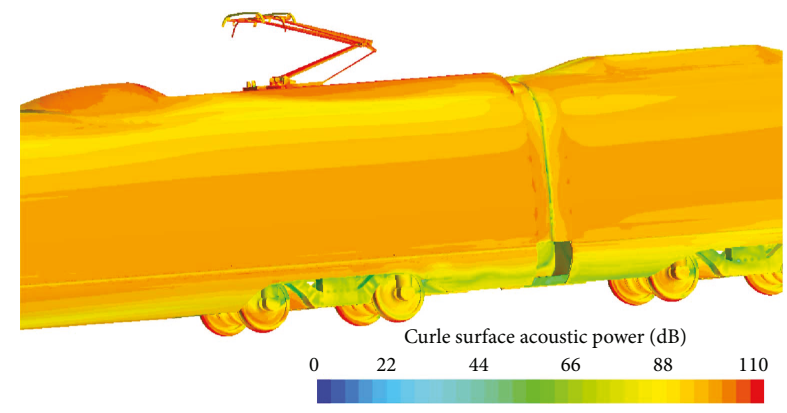

(d) Pantograph area

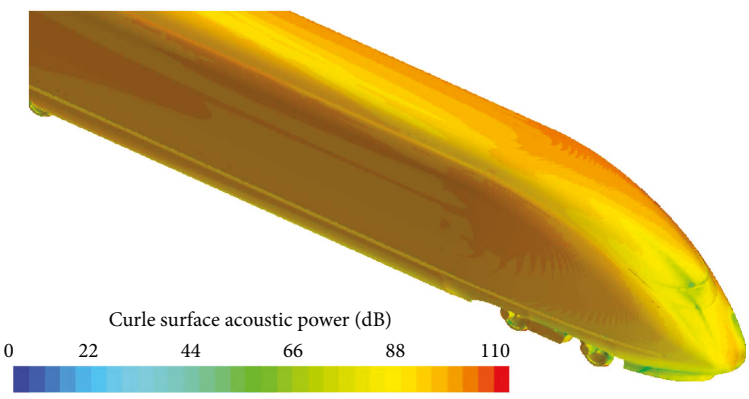

(e) Tail railway

Figure 10: Surface dipole noise of high-speed railways running on bridges.

sound pressure level in the pantograph fairing areas was $3.1 \mathrm{dBA}$ smaller than the maximum sound pressure level when it is running on the bridge.

Table 1 shows comparison of sound pressure levels on horizontal monitoring points with different distances from the head railway. Table 1 shows the following: as for horizontal monitoring points at the head nose tip, which were $8 \mathrm{~m}$, $14 \mathrm{~m}, 20 \mathrm{~m}, 26 \mathrm{~m}$, and $32 \mathrm{~m}$ away from the track center line, the decrease amplitudes of sound pressure levels were $2.1 \mathrm{dBA} \rightarrow 2.3 \mathrm{dBA} \rightarrow 0.5 \mathrm{dBA} \rightarrow 1.2 \mathrm{dBA}$; as for horizontal monitoring points near the first-end bogie of the head railway, the decrease amplitudes of sound pressure levels were $0.9 \mathrm{dBA} \rightarrow 0.6 \mathrm{dBA} \rightarrow 2.1 \mathrm{dBA} \rightarrow 1.4 \mathrm{dBA}$; as for horizontal measurement points of the second-end bogie of the head railway, the decrease amplitudes of sound pressure levels were $0.5 \mathrm{dBA} \rightarrow 0.8 \mathrm{dBA} \rightarrow 0.5 \mathrm{dBA} \rightarrow 0.1 \mathrm{dBA}$; as for horizontal monitoring points on the first end of air barrier, the decrease amplitudes of sound pressure levels were $3.4 \mathrm{dBA} \rightarrow 0.9 \mathrm{~d}$ $\mathrm{BA} \rightarrow 1.1 \mathrm{dBA} \rightarrow 0.2 \mathrm{dBA}$; as for horizontal monitoring points near first-end bogie of the mid railway, the decrease amplitudes of sound pressure levels were $0.9 \mathrm{dBA} \rightarrow 1.2 \mathrm{~d}$ $\mathrm{BA} \rightarrow 0.4 \mathrm{dBA} \rightarrow 0.1 \mathrm{dBA}$; as for horizontal monitoring points near the second-end bogie of the mid railway, the decrease amplitudes of sound pressure levels were $0.6 \mathrm{dBA} \rightarrow 0.9 \mathrm{dBA} \rightarrow 0.5 \mathrm{dBA} \rightarrow 0.1 \mathrm{dBA}$; as for horizontal monitoring points near second end of the air barrier, the decrease amplitudes of sound pressure levels were $3.3 \mathrm{dBA} \rightarrow 0.6 \mathrm{dBA} \rightarrow 0.6 \mathrm{dBA} \rightarrow 0.2 \mathrm{dBA}$; as for horizontal monitoring points near second-end bogie of the tail railway, the decrease amplitudes of sound pressure levels were $0.4 \mathrm{dBA} \rightarrow 0.9 \mathrm{dBA} \rightarrow 0.5 \mathrm{dBA} \rightarrow-0.2 \mathrm{dBA}$; as for horizontal monitoring points near the first-end bogie of the tail railway, the decrease amplitudes of sound pressure levels were $0.1 \mathrm{dBA} \rightarrow 0.1 \mathrm{dBA} \rightarrow 1.8 \mathrm{dBA} \rightarrow 1.5 \mathrm{dBA}$; and as for horizontal monitoring points near the tail nose tip, the decrease amplitudes of sound pressure levels were $2.3 \mathrm{dBA} \rightarrow 1.1 \mathrm{~d}$ $\mathrm{BA} \rightarrow 0.8 \mathrm{dBA} \rightarrow 1.2 \mathrm{dBA}$. This result indicates that sound pressure levels of monitoring points decreased with the increase of distance away from the track center line. The horizontal maximum attenuation amplitudes of aerodynamic 


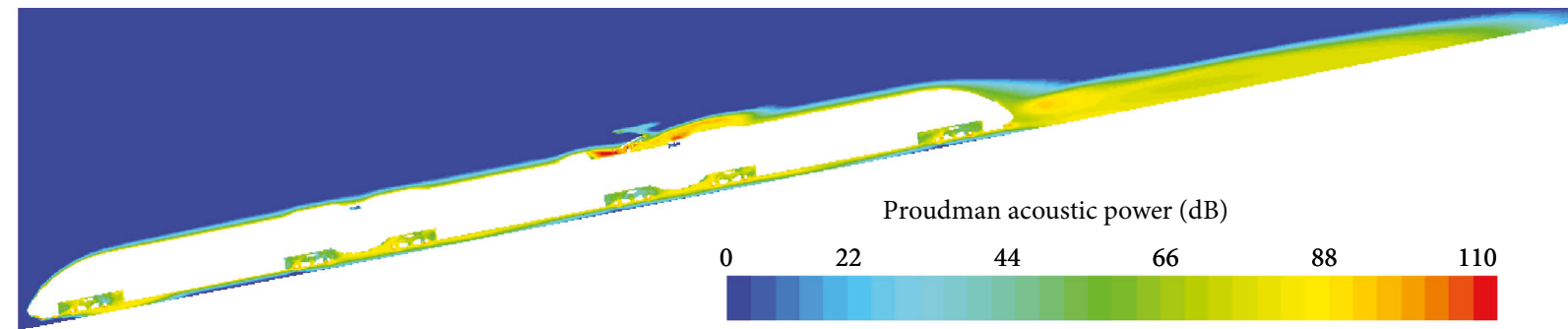

(a) $y=0 \mathrm{~m}$ longitudinal cross section

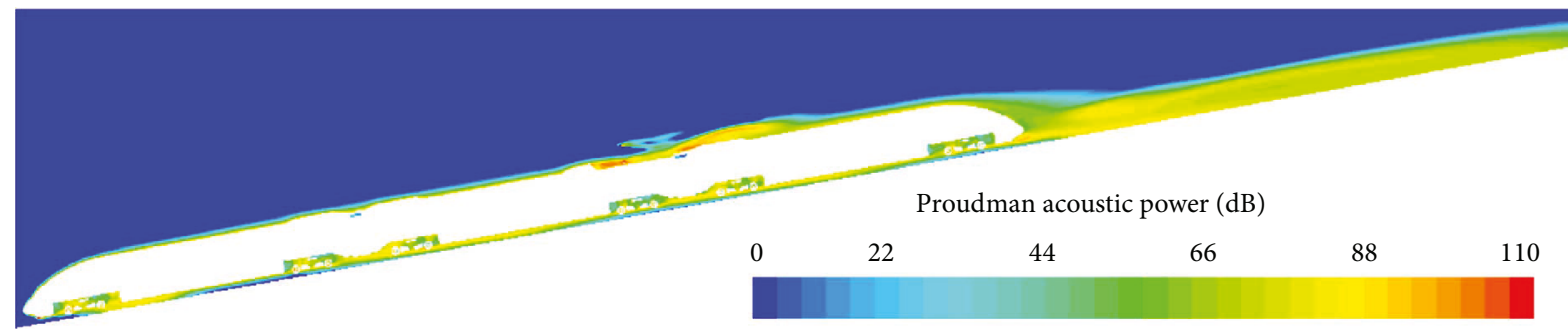

(b) $y=0.05 \mathrm{~m}$ longitudinal cross section

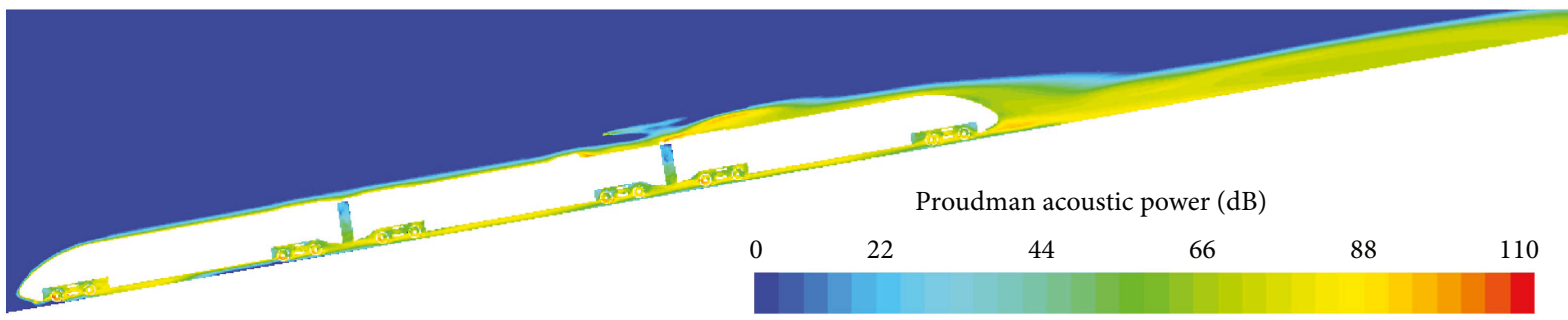

(c) $y=0.1 \mathrm{~m}$ longitudinal cross section

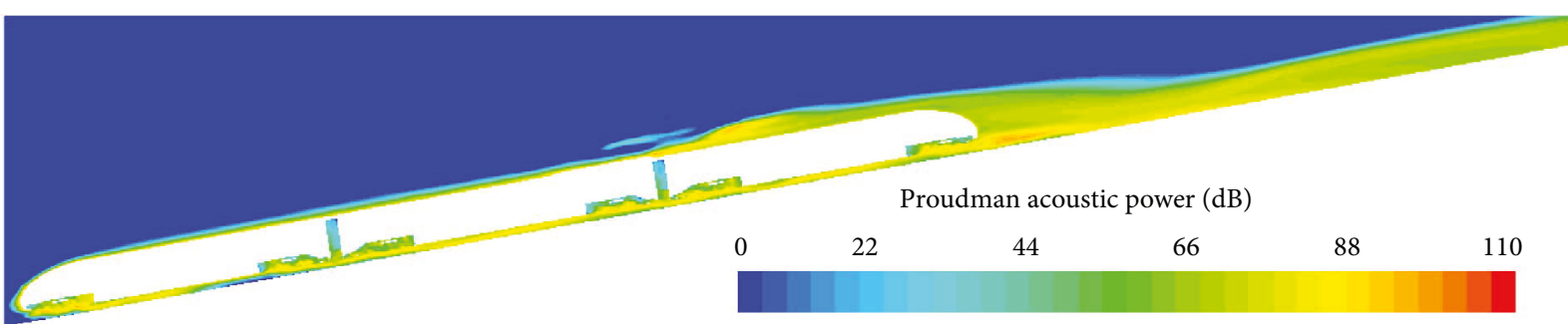

(d) $y=0.15 \mathrm{~m}$ longitudinal cross section

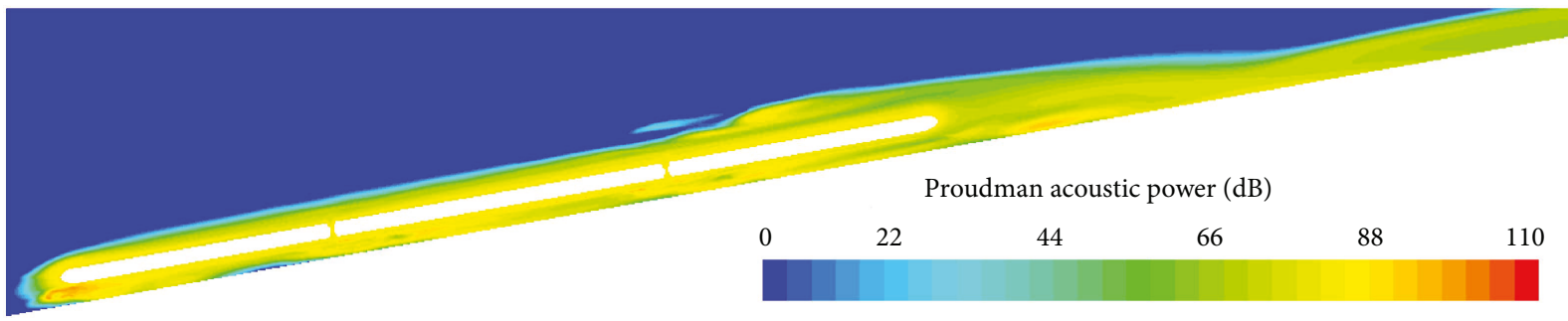

(e) $y=0.2 \mathrm{~m}$ longitudinal cross section

FIGURE 11: Quadrupole noise around the high-speed railway on bridges.

nose pressure levels ranged within 1.8 dBA 6.1 dBA. The sound pressure level amplitudes got most attenuation at the head nose tip, first-end air barrier, tail nose tip, and second-end air barrier. To reduce far-field noise radiation of this part, the best method is to improve and optimize noise sources of this part and reduce noise pressure levels on the railway surface in succession. In this way, radiation of far-field aerodynamic noise can be reduced. The minimum sound pressure level attenuation amplitudes appeared at the second-end bogie of the mid railway and the second-end bogie of the tail railway. Amplitudes of the second-end bogie of the head railway and first-end bogie of the mid railway ranked the second place. Hence, obviously, to reduce farfield noise radiation, the best method is to reduce parts with small sound pressure level attenuation amplitudes (secondend bogie of the mid railway, second-end bogie of the tail 


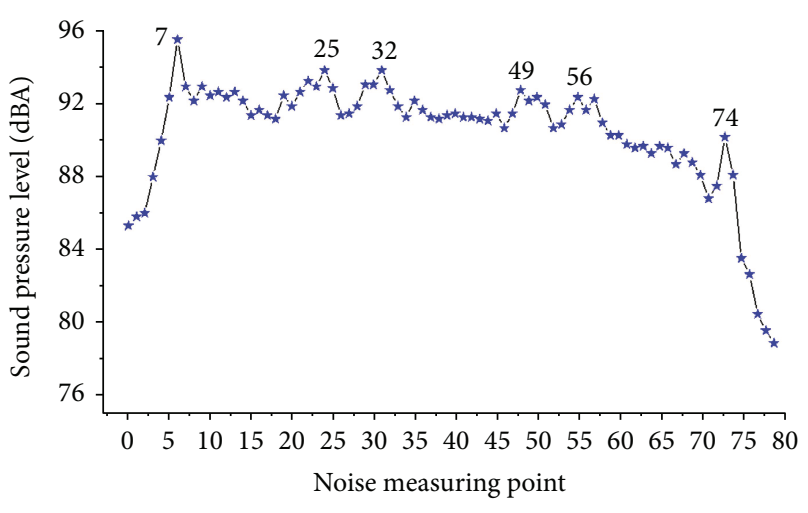

FIGURE 12: Aerodynamic noise level of high-speed railways on bridges.

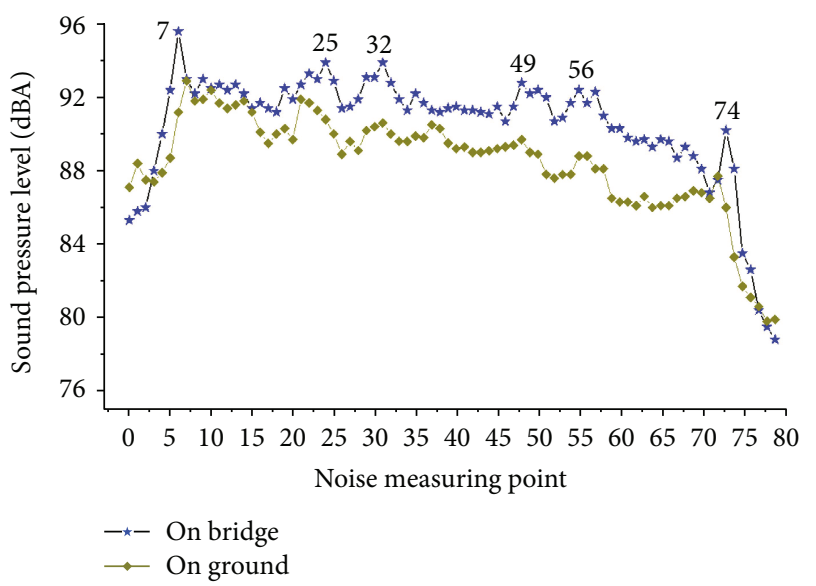

FIGURE 13: Comparison of aerodynamic noise levels under different road situations.

railway, second-end bogie of the head railway, and first-end bogie of the mid railway). Far-field aerodynamic noise can be reduced through sound insulation. Horizontal attenuation values of noise monitoring points were large at the first-end air barrier and the second-end air barrier, where the longitudinal maximum value appeared at the position of $8 \mathrm{~m}$. Obviously, to improve far-field noise radiation at air barriers, the noise monitoring points should be arranged within $8 \mathrm{~m}$ scope away from the track center line. Sound pressure level attenuation of longitudinal noise was not large, where sound pressure levels were distributed within 12.3 dBA 12.8 dBA. Obviously, among the longitudinal noise monitoring points, attenuation values of sound pressure levels of the monitoring points were similar and not quite different.

At positions which were $3.5 \mathrm{~m}$ higher above the track and $3 \mathrm{~m}, 8 \mathrm{~m}, 18 \mathrm{~m}, 38 \mathrm{~m}$, and $78 \mathrm{~m}$ away from the head nose tip and tail nose tip (distance between two adjacent monitoring points satisfies 2-multiple relation), 10 noise monitoring points were arranged along the longitudinal direction of the railway. Figure 14 gives the A-weighting comparison diagram of sound pressure levels at noise monitoring points of longitudinal symmetric lines of the high-speed railway. As shown by noise radiation noise pressure levels at the noise monitoring points on the longitudinal symmetric line, which had different distances from the nose tip, in the direction of incoming flow, sound pressure levels at noise monitoring points which had different distances from the head nose tip got attenuated. As for longitudinal monitoring points at longitudinal symmetric lines, which were $3 \mathrm{~m}, 8 \mathrm{~m}, 18 \mathrm{~m}, 38 \mathrm{~m}$, and $78 \mathrm{~m}$ away from the head nose tip, the sound pressure level decrease amplitudes of the high-speed railway were $3.9 \mathrm{dBA} \rightarrow 4.1 \mathrm{dBA} \rightarrow 3.2 \mathrm{dBA} \rightarrow 1.5 \mathrm{dBA}$. In the reverse wake flow direction, sound pressure levels at noise monitoring points which had different distances from the head nose tip got attenuated. As for longitudinal monitoring points on longitudinal symmetric lines, which were $3 \mathrm{~m}, 8 \mathrm{~m}, 18 \mathrm{~m}$, $38 \mathrm{~m}$, and $78 \mathrm{~m}$ away from the tail nose tip, the attenuation amplitudes of sound pressure levels were $1.7 \mathrm{dBA} \rightarrow 2.6 \mathrm{~d}$ $\mathrm{BA} \rightarrow 2.5 \mathrm{dBA} \rightarrow 0.9 \mathrm{dBA}$. Values of monitoring points in the incoming flow direction were $5.3 \mathrm{dBA}, 3.1 \mathrm{dBA}$, 1.6 dBA, $0.9 \mathrm{dBA}$, and $0.3 \mathrm{dBA}$ larger than those of monitoring points in the wake flow direction. Obviously, incoming flows brought more aerodynamic noise effects around the railway body compared with wake flow aerodynamic noise. In the direction of incoming flow, linear relations existed between sound pressure levels of noise monitoring points $(3 \mathrm{~m}, 8 \mathrm{~m}, 18 \mathrm{~m}, 38 \mathrm{~m}$, and $78 \mathrm{~m})$ which had different distances from the head nose tip and logarithms of the monitoring point distances. They satisfy the following fitting relation.

$$
P_{A}=-9.36 \log (S)+101.28 \text {. }
$$

In formula (5), $S$ denotes the distance of monitoring point in the incoming flow direction.

In the wake flow direction, linear relationship existed between sound pressure levels of noise monitoring points $(3 \mathrm{~m}, 8 \mathrm{~m}, 18 \mathrm{~m}, 38 \mathrm{~m}$, and $78 \mathrm{~m})$ which had different distances from the tail nose tip and monitoring point distances. Through fitting of a polynomial, the following function relation can be obtained:

$$
P_{A}=-5.83 \log (S)+94.73 .
$$

Figure 15 shows distribution contours of turbulence energy on the bridge and ground surface, which was generated when the high-speed railway ran at $350 \mathrm{~km} / \mathrm{h}$ on the bridge and ground. Through comparative analysis on Figure 15, we can find that high turbulence energy distribution was formed on the upper side of the bridge frame due to impacts brought by the bridge plate structure to aerodynamic noise of the high-speed railway, whereas large turbulence energy was not formed on the ground. When the high-speed railway passed the bridge, noise radiation of bridge rods would be generated. Hence, bridge rod parts also belong to a major aerodynamic noise source and could intensify propagation of the high-speed railway aerodynamic nose on the bridge. Therefore, in comparison with the high-speed railway running on the ground, influences brought by the aerodynamic noise of the high-speed railway on the bridge are more serious than those brought during ground running.

The paper conducted spectral analysis on noise of the railway based on linear frequency spectra and power spectral density. The power spectral density is a rapid method for 
TABLE 1: Comparison table of sound pressure levels on horizontal monitoring points.

\begin{tabular}{lcccccc}
\hline Positions from the head nose tip & $8 \mathrm{~m}$ & $14 \mathrm{~m}$ & $20 \mathrm{~m}$ & $26 \mathrm{~m}$ & $32 \mathrm{~m}$ & Horizontal maximum attenuation value \\
\hline Head nose tip & 90.5 & 88.4 & 86.1 & 85.6 & 84.4 & 6.1 \\
First-end bogie of the head railway & 95.5 & 94.6 & 94 & 91.9 & 90.5 & 5.0 \\
Second-end bogie of the head railway & 94.6 & 94.1 & 93.3 & 92.8 & 92.9 & 1.8 \\
First-end air barrier & 97.5 & 94.1 & 93.2 & 92.1 & 91.9 & 5.6 \\
First-end bogie of the mid railway & 95.0 & 94.1 & 92.9 & 92.5 & 92.4 & 2.6 \\
Second-end bogie of the mid railway & 93.5 & 92.9 & 92 & 91.5 & 91.6 & 2.0 \\
Second-end air barrier & 95.6 & 92.3 & 91.7 & 91.1 & 90.9 & 4.7 \\
Second-end bogie of the tail railway & 93.2 & 92.8 & 91.8 & 91.3 & 91.5 & 3.9 \\
First-end bogie of the tail railway & 90.7 & 90.6 & 90.5 & 88.7 & 87.2 & 5.4 \\
Tail nose tip & 84.7 & 82.4 & 81.3 & 80.5 & 79.3 & - \\
Longitudinal maximum attenuation value & 12.8 & 12.2 & 12.7 & 12.3 & 13.6 & \\
\hline
\end{tabular}

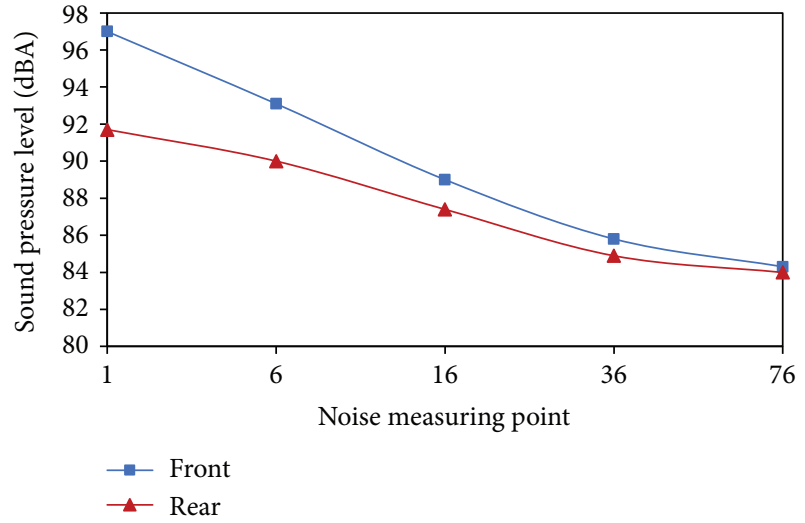

FIGURE 14: Comparison of sound pressure levels on longitudinal monitoring points.

noise signal processing of short signals with the Welch method [29]. The method is most advantageous in that it can reduce the variance problem existing in short signal processing. During power spectral density analysis, short signals are divided into 5 sections for processing. All the parts are overlaid by $50 \%$ separately. Meanwhile, the Hanning window function was used for windowing of each part. Finally, averaging and compensating computation was conducted to the 5-section signal. Finally, the power spectral density of the complete signal could be obtained. Figure 16(a) gives a linear spectrum curve of the noise assessment point 7 (position of the maximum longitudinal sound pressure level). Figure 16(b) gives a power spectral density curve of noise assessment point 7 (position of the maximum longitudinal sound pressure level). Through analysis on Figure 16, we can find that far-field noise of the railway had wide spectra, belonging to broadband noise. Main energy of aerodynamic noise was concentrated within $630 \mathrm{~Hz} 5000 \mathrm{~Hz}$. Distribution scopes of main energy frequencies were related to positions away from the head nose tip. When the position was farther from the nose tip, the $1 / 3$ octave main frequency scope tended to move to high frequencies. Within $25 \mathrm{~Hz} \sim 630 \mathrm{~Hz}$, the $1 / 3$ octave amplitudes of aerodynamic nose increased rapidly with the increase of frequency. When the frequency exceeded $630 \mathrm{~Hz}$, the $1 / 3$ octave of aerodynamic noise did not change a lot with the increase of frequency.

\section{Conclusions}

Based on the Lighthill acoustic theory, the paper conducted numerical research on unsteady aerodynamic flow characteristic of the high-speed railway on the bridge through detached eddy simulation. Meanwhile, the broadband noise source model was used for numerical prediction of dipole noise sources and quadrupole noise sources of the highspeed railway on the bridge. Detached eddy simulation and Lighthill acoustic analogy theory were used for numerical computation of aerodynamic nose of the high-speed railway. Far-field aerodynamic noise characteristics of the high-speed railway were analyzed. During modeling, according to an aerodynamic model with consideration of detailed structures of the railway (pantograph area, pantograph, bogie, air conditioning unit, end joint, and so forth), an aerodynamic noise model of a marshalling high-speed railway on the bridge was established. The following conclusions are obtained:

(1) Eddy shedding and fluid separation are main reasons for formatting the high-speed railway aerodynamic noise. Main aerodynamic noise sources of a pantograph are distributed at the pantograph head, joints between the upper arm rod and lower arm rod, and the chassis area. Compared with other 5 bogies, the first-end bogie of the head railway is the major aerodynamic noise source. Pantograph, pantograph area, streamline area of the head, bogie, bogie area, air barrier areas, air conditioning unit areas, and so forth are main aerodynamic noise sources of the high-speed railway.

(2) Far-field noise of the railway has a wide frequency spectrum, belonging to broadband noise. Main energy is centralized within $630 \mathrm{~Hz} 5000 \mathrm{~Hz}$. With the increase of the running speed, the far-field aerodynamic noise energy moves to high frequencies.

(3) Through comparative analysis on total noise levels at monitoring points of the high-speed railway 


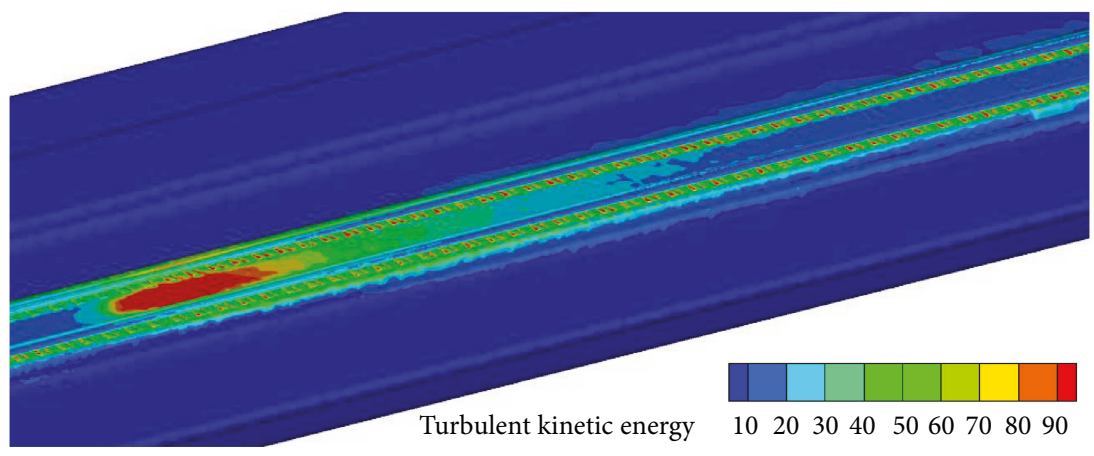

(a) Bridge

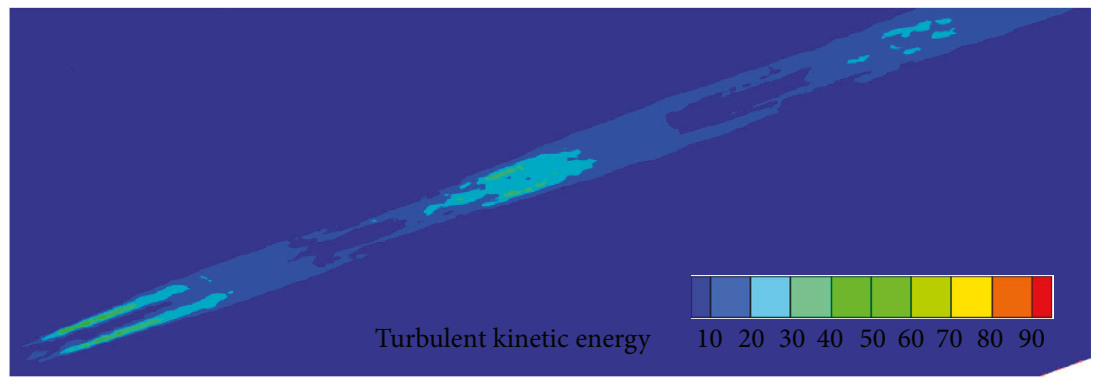

(b) Ground

FIGURE 15: Comparison of turbulence energy under different road situations.

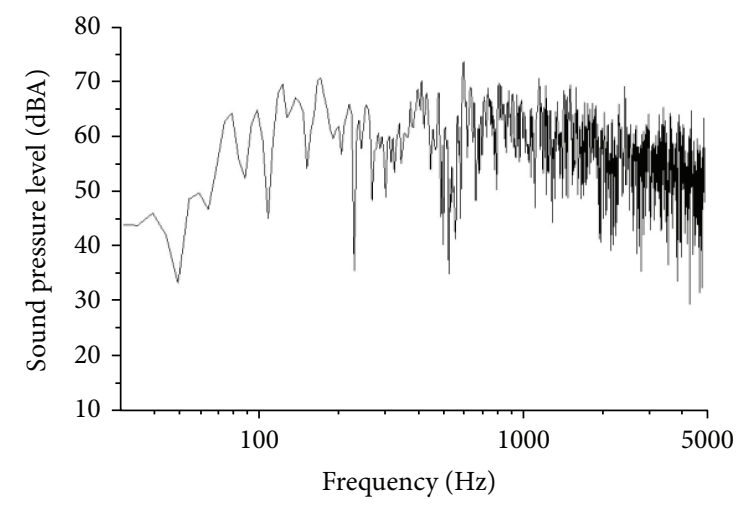

(a) Linear frequency spectrum

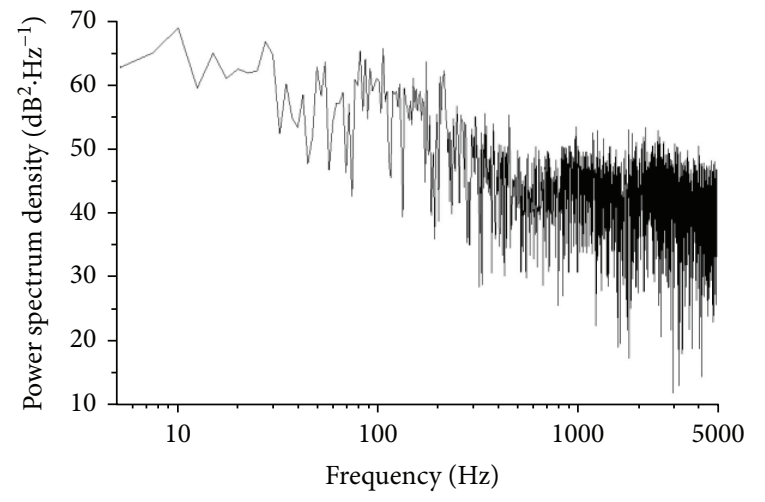

(b) Density of power spectrum

FIGURE 16: Aerodynamic noise spectrum of high-speed railways on bridges.

(position $25 \mathrm{~m}$ away from the track center line and $3.5 \mathrm{~m}$ higher above the track face), we can find that along the running direction, locally maximum sound pressure levels of the longitudinal sound pressure level distribution curves appeared at the first-end bogie of the head railway, second-end bogie of the head railway, first-end bogie of the mid railway, second-end bogie of the mid railway, second-end bogie of the tail railway, and first-end bogie of the tail railway. To reduce total noise pressure levels of the complete railway, key noise reduction measures can be conducted at these 6 positions. In this way, the noise reduction effect would be obvious.
(4) Computation results of sound pressure levels on longitudinal monitoring points show that incoming flows had large impacts on aerodynamic nose around the railway body compared with wake flow aerodynamic noise. Additionally, in directions of incoming flow and wake flow, linear relations existed between sound pressure levels of noise monitoring points which had different distances from the head node tip ( $3 \mathrm{~m}, 8 \mathrm{~m}, 18 \mathrm{~m}, 38 \mathrm{~m}$, and $78 \mathrm{~m}$ ) and logarithms of monitoring point distances.

(5) When the railway ran at $350 \mathrm{~km} / \mathrm{h}$, the maximum sound pressure level and average sound pressure level 
of the high-speed railway on the bridge would be 95.6 dBA and 91.9 dBA, respectively, while the maximum sound pressure level in the pantograph fairing area was $92.8 \mathrm{dBA}$. When the railway ran on the flat ground, the maximum sound pressure level of farfield noise was $92.9 \mathrm{dBA}$, with the average sound pressure level of $89.6 \mathrm{dBA}$, while the maximum sound pressure level in the pantograph fairing area was $89.7 \mathrm{dBA}$. In conclusion, the maximum sound pressure level and average sound pressure level of the high-speed railway when it is running on the bridge were $2.7 \mathrm{dBA}$ and $2.3 \mathrm{dBA}$, respectively, larger than those under working conditions of flat ground running. On the bridge, the maximum sound pressure level in the pantograph fairing area was 3.1 dBA larger than that of the flat ground. Therefore, how to avoid and reduce the aerodynamic noise of high-speed railways running on the bridge should be studied and expected in the future in conclusions. For example, we can arrange the wind barrier on the bridge to reduce the radiated noise of the running high-speed railway.

\section{Data Availability}

The data used to support the findings of this study are available from the corresponding author upon request.

\section{Conflicts of Interest}

The authors declare that they have no conflicts of interest.

\section{References}

[1] J. Y. Zhu, Z. W. Hu, and D. J. Thompson, "Flow simulation and aerodynamic noise prediction for a high-speed train wheelset," International Journal of Aeroacoustics, vol. 13, no. 7-8, pp. 533-552, 2014.

[2] Z. Yang, Z. Q. Gu, Y. P. Wang, J. R. Yan, and X. T. Yang, "Prediction and optimization of aerodynamic noise in an automotive air conditioning centrifugal fan," Journal of Central South University, vol. 20, no. 5, pp. 1245-1253, 2013.

[3] J. L. Liu, J. Y. Zhang, and W. H. Zhang, "Study of computational method of far-field aerodynamic noise of a high-speed train considering ground effect," Chinese Journal of Computational Mechanics, vol. 30, no. 1, pp. 94-100, 2013.

[4] J. Muñoz-Paniagua, J. García, and A. Crespo, "Genetically aerodynamic optimization of the nose shape of a high-speed train entering a tunnel," Journal of Wind Engineering and Industrial Aerodynamics, vol. 130, pp. 48-61, 2014.

[5] Z. Y. Shen, "Dynamic environment of high-speed train and its distinguished technology," Journal of the China Railway Society, vol. 28, no. 4, pp. 1-5, 2006.

[6] W. H. Zhang, "Study on top-level design specifications of high-speed trains," Journal of the China Railway Society, vol. 34, no. 9, pp. 15-19, 2012.

[7] X.-s. Jin, "Key problems faced in high-speed train operation," Journal of Zhejiang University Science A, vol. 15, no. 12, pp. 936-945, 2014.
[8] D. J. Thompson, E. Latorre Iglesias, X. Liu, J. Zhu, and Z. Hu, "Recent developments in the prediction and control of aerodynamic noise from high-speed trains," International Journal of Rail Transportation, vol. 3, no. 3, pp. 119-150, 2015.

[9] E. Latorre Iglesias, D. J. Thompson, M. Smith, T. Kitagawa, and N. Yamazaki, "Anechoic wind tunnel tests on highspeed train bogie aerodynamic noise," International Journal of Rail Transportation, vol. 5, no. 2, pp. 87-109, 2017.

[10] S. G. Zhang, "Noise mechanism, sound source localization and noise control of $350 \mathrm{~km} \cdot \mathrm{h}^{-1}$ high-speed train," China Railway Science, vol. 30, no. 1, pp. 86-90, 2009.

[11] T. Kitagawa and K. Nagakura, "Aerodynamic noise generated by Shinkansen cars," Journal of Sound and Vibration, vol. 231, no. 3, pp. 913-924, 2000.

[12] K. Nagakura, "Localization of aerodynamic noise sources of Shinkansen trains," Journal of Sound and Vibration, vol. 293, no. 3-5, pp. 547-556, 2006.

[13] Z. Y. Zheng and R. X. Li, "Numerical analysis of aerodynamic dipole source on high-speed train surface," Journal of Southwest Jiaotong University, vol. 46, no. 6, pp. 9961002, 2011.

[14] Y. Gao, Y. G. Wang, J. T. Wang, Z. Shen, and Z. G. Yang, "Testing study of aerodynamic noise for high speed train model in aero-acoustic wind tunnel," Technical Acoustics, vol. 32, no. 6, pp. 506-510, 2013.

[15] E. Latorre Iglesias, D. J. Thompson, and M. G. Smith, "Component-based model to predict aerodynamic noise from high-speed train pantographs," Journal of Sound and Vibration, vol. 394, pp. 280-305, 2017.

[16] N. Yamazaki, T. Takaishi, M. Toyooka, K. Nagakura, A. Sagawa, and H. Yano, "Wind tunnel tests on the control of aeroacoustic noise from high speed train," in Noise and Vibration Mitigation for Rail Transportation Systems, pp. 3339, Springer, Berlin, Heidelberg, 2008.

[17] Y. Wakabayashi, T. Kurita, H. Yamada, and M. Horiuchi, "Noise measurement results of Shinkansen high-speed test train (FASTECH360S, Z)," in Noise and Vibration Mitigation for Rail Transportation Systems, pp. 63-70, Springer, Berlin, Heidelberg, 2008.

[18] T. Kurita, "Development of external-noise reduction technologies for Shinkansen high-speed trains," Journal of Environment and Engineering, vol. 6, no. 4, pp. 805-819, 2011.

[19] H. M. Noh, S. Choi, S. Hong, and S. W. Kim, "Investigation of noise sources in high-speed trains," Proceedings of the Institution of Mechanical Engineers, Part F: Journal of Rail and Rapid Transit, vol. 228, no. 3, pp. 307-322, 2014.

[20] Y. G. Xiao and Z. C. Kang, "Numerical prediction of aerodynamic noise radiated from high speed train head surface," Journal of Central South University: Science and Technology, vol. 39, no. 6, pp. 1267-1272, 2008.

[21] J. L. Liu, J. Y. Zhang, and W. H. Zhang, "Numerical analysis on aerodynamic noise of the high-speed train head," Journal of the China Railway Society, vol. 33, no. 9, pp. 19-26, 2011.

[22] Z. Sun, J. Song, and Y. An, "Numerical simulation of aerodynamic noise generated by high speed trains," Engineering Applications of Computational Fluid Mechanics, vol. 6, no. 2, pp. 173-185, 2012.

[23] Z. Sun, D. Guo, S. Yao, G. Yang, and M. Li, "Identification and suppression of noise sources around high speed trains," Engineering Applications of Computational Fluid Mechanics, vol. 7, no. 1, pp. 131-143, 2013. 
[24] S. Huang, M. Z. Yang, and Z. W. Li, "Aerodynamic noise numerical simulation and noise reduction of high-speed train bogie section," Journal of Central South University: Science and Technology, vol. 42, no. 12, pp. 3899-3904, 2011.

[25] J. E. F. Williams and D. L. Hawkings, "Sound generation by turbulence and surfaces in arbitrary motion," Philosophical Transactions of the Royal Society A: Mathematical, Physical and Engineering Sciences, vol. 264, no. 1151, pp. 321-342, 1969.

[26] M. J. Lighthill, "On sound generated aerodynamically I. General theory," Proceedings of the Royal Society A: Mathematical, Physical and Engineering Sciences, vol. 211, no. 1107, pp. 564587, 1952.

[27] I. Proudman, "The generation of noise by isotropic turbulence," Proceedings of the Royal Society A: Mathematical, Physical and Engineering Sciences, vol. 214, no. 1116, pp. 119-132, 1952.

[28] G. M. Lilley, "The radiated noise from isotropic turbulence," Theoretical and Computational Fluid Dynamics, vol. 6, no. 56, pp. 281-301, 1994.

[29] P. Welch, "The use of fast Fourier transform for the estimation of power spectra: a method based on time averaging over short, modified periodograms," IEEE Transactions on Audio and Electroacoustics, vol. 15, no. 2, pp. 70-73, 1967. 


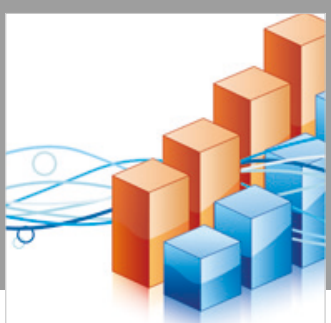

Advances in

Operations Research

\section{-n-m}
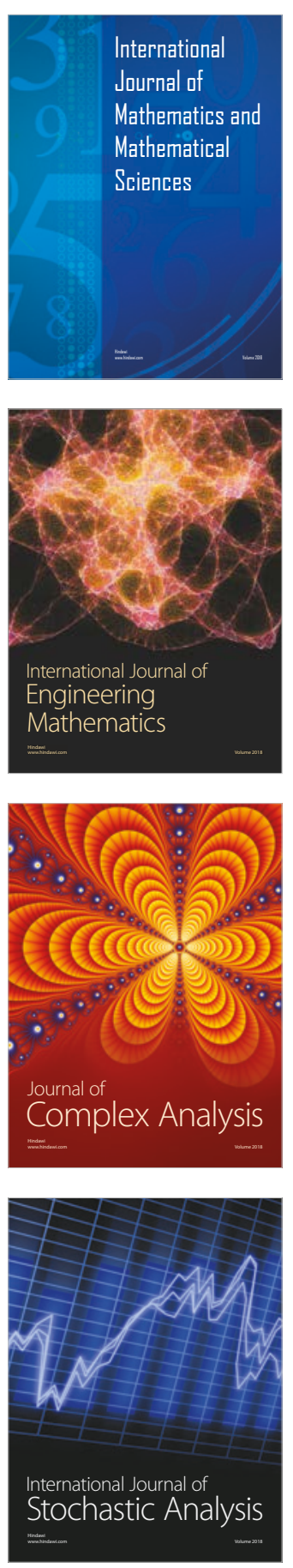
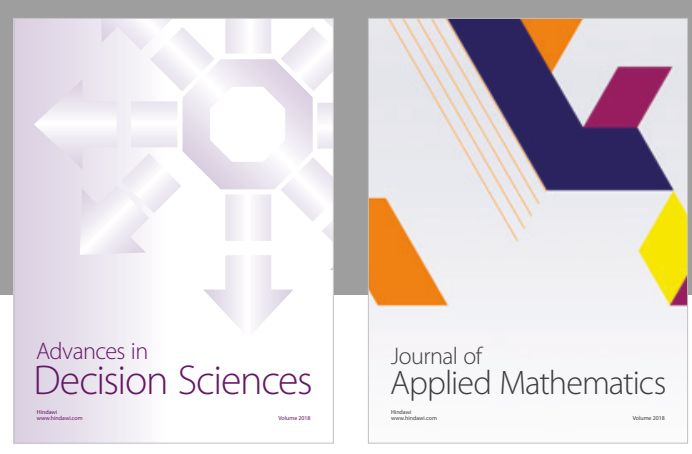

Journal of

Applied Mathematics
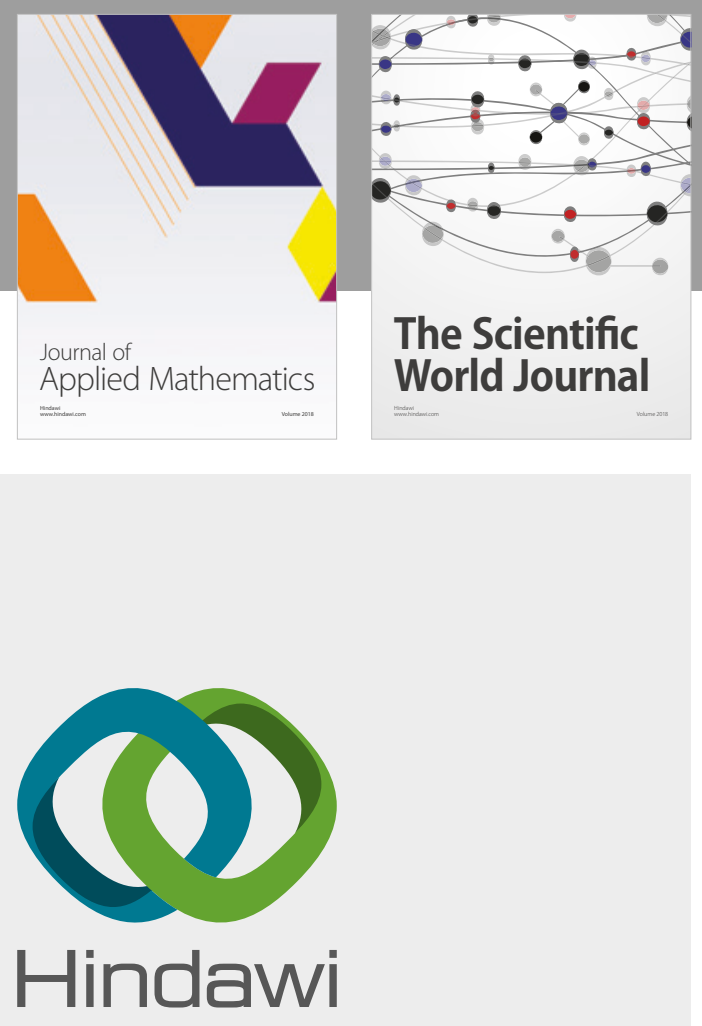

Submit your manuscripts at

www.hindawi.com

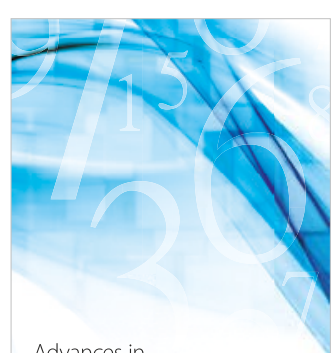

Advances in
Numerical Analysis
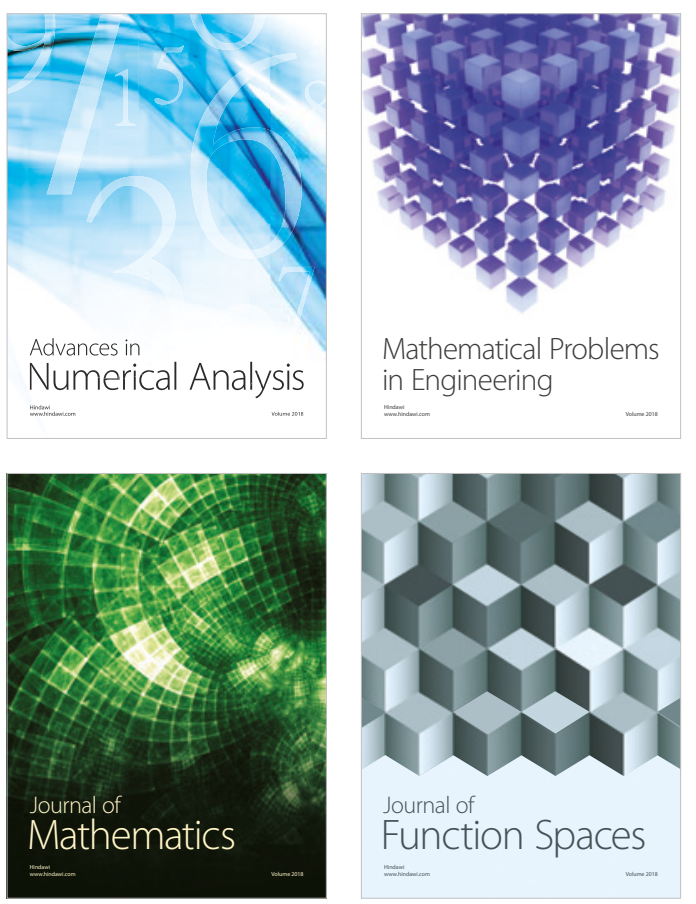

Mathematical Problems in Engineering

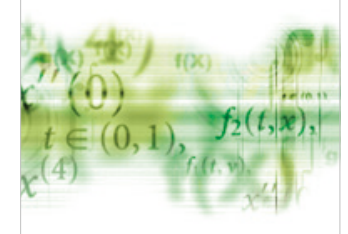

International Journal of

Differential Equations

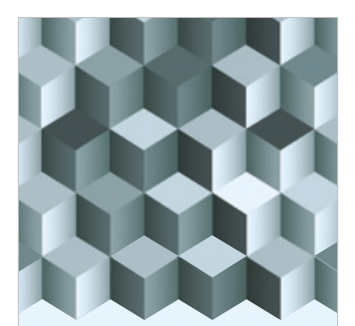

Journal of

Function Spaces
The Scientific

World Journal

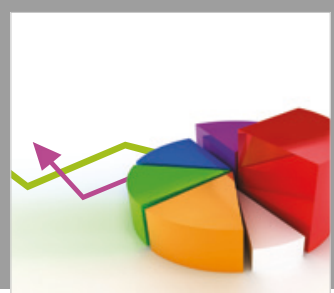

Journal of

Probability and Statistics
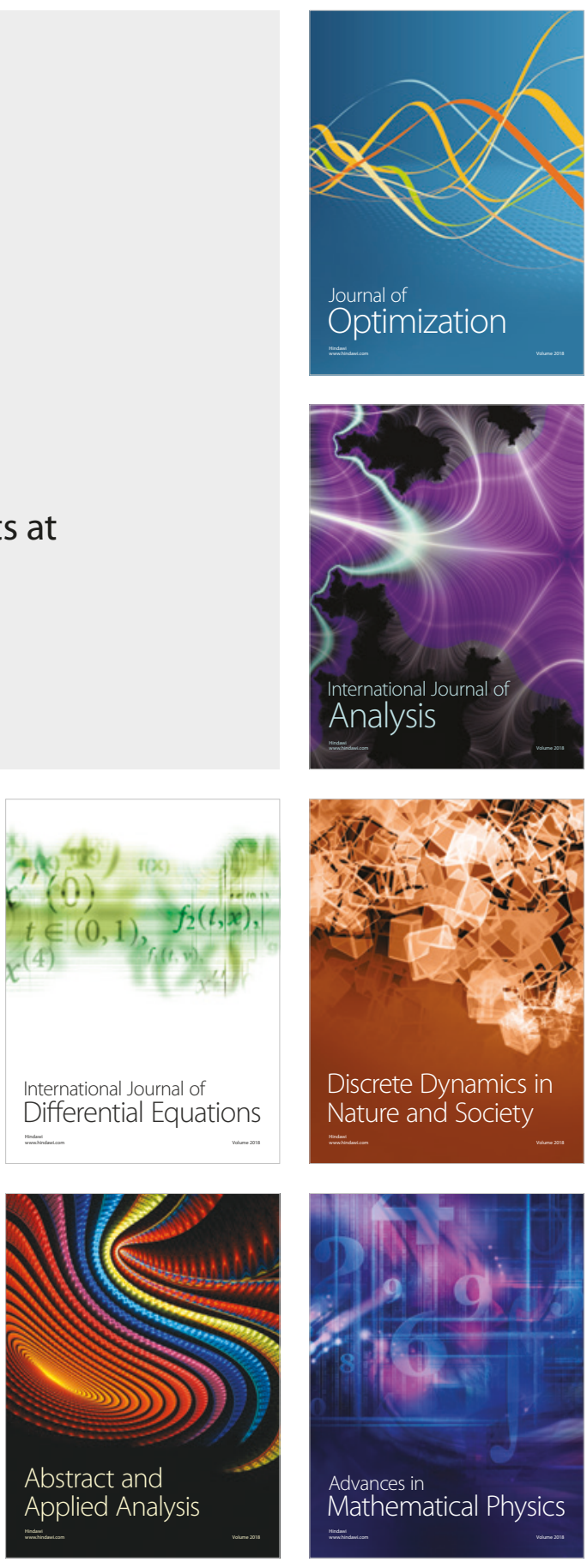